\title{
Comparative assessment of large-scale marine eutrophication: North Sea area and Adriatic Sea as case studies
}

\author{
Jean-Noël Druon*, Wolfram Schrimpf, Srdjan Dobricic, Adolf Stips \\ European Commission, Joint Research Centre, Institute for Environment \& Sustainability, Inland \& Marine Waters Unit, \\ TP 272, 21020 Ispra (VA), Italy
}

\begin{abstract}
In the last $50 \mathrm{yr}$, marginal seas under freshwater influence have become affected by eutrophication. The large areas involved render its assessment difficult. In this paper, a spatial and comparative approach is presented assuming that hydromorphology together with organic matter production control the various consequences of nutrient overenrichment. We have developed 2 eutrophication indices of shallow marine ecosystems using hydrodynamic modelling and optical satellite remote-sensing. The indices are tested in systems characterised by contrasting physical regimes, i.e. the Adriatic and North Sea. The physically sensitive area index (PSA) integrates the supporting factors of eutrophication, i.e. the physical conditions driving primary production in the upper layer and oxygen availability near the bottom. The eutrophication risk index (EUTRISK) characterises the spatial distribution of potential hypoxia at a monthly timescale. It is based on an oxygen budget between the physical capacity to store and renew the oxygen near the seabed and the flux of organic matter reaching the sediment, estimated primarily from satellite-derived chlorophyll a data. The indices identify 3 main types of eutrophicated waters: (1) eutrophic and sensitive, (2) mesotrophic and sensitive and (3) eutrophic and resistant. In Category 1 oxygen depletion occurs recurrently because both the main pressure and supporting factors are unfavourable (e.g. coastal waters south of the Po river mouth). In Category 2, severe hypoxia or anoxia occur due to particularly adverse physical conditions, even when primary production is relatively low (e.g. the Kattegat and NE part of the northern Adriatic Sea). Category 3 comprises areas where severe hypoxia near the seabed is prevented by permanent tidally induced vertical mixing; however nutrient overenrichment is recognised as leading to alterations in the food-web structure and functioning (e.g. Bay of Seine). The EUTRISK index forms the basis of a comparative tool for the assessment and monitoring of marine eutrophication risk. The PSA index, which provides an understanding of physical vulnerability on a large scale, indicates the relative threshold of nutrient discharge, i.e. the assimilative capacity of marine ecosystems. This first assessment of the underlying processes controlling marine eutrophication is a prerequisite for efficient restoration strategies on a large scale.
\end{abstract}

KEY WORDS: Marine eutrophication · Physical sensitivity $\cdot$ Hydromorphology · Oxygen deficiency · Environmental tool $\cdot$ Optical remote-sensing $\cdot$ Numerical modelling $\cdot$ Adriatic Sea $\cdot$ North Sea area

\section{INTRODUCTION}

The eutrophication process has not always been seen as a negative effect on aquatic ecosystems, being qualified as 'positive' for fisheries globally in the 1950s (Thurow 1999) and more recently on a regional scale
(Marasovic et al. 1988, Josefson \& Rasmussen 2000). It was associated with 'vulnerability' of the ecosystem in the 1960s (Harwood et al. 1990, Hagen \& Kleeberg 1994) and termed 'risk society' in the 1990s (Archer \& Mark 1997, Wilson et al. 1999). The combat of eutrophication represents one of the major objectives dis- 
cussed at the various Marine Conventions (Helsinki, 1974 and 1992; Barcelona, 1976; Oslo-Paris [OSPAR], 1992) and is clearly tackled by the European Communities $(1991 \mathrm{a}, \mathrm{b})$ Nitrates and Urban Waste Water Directives (91/676/EEC and 91/271/EEC).

Eutrophication was defined by Nixon (1995) as 'an increase in the rate of supply of organic matter to an ecosystem'. Besides this main direct effect, an holistic assessment of eutrophication should include causative factors (e.g. nutrient enrichment), supporting environmental factors (e.g. hydromorphological conditions), and indirect effects (e.g. oxygen deficiencies or changes in benthic community structure). Indicators are essential to monitor changes in the state of coastal and marine environments, to assess trends in socioeconomic pressures and conditions in the coastal areas, and to appraise the effectiveness of integrated coastal management (Mageau \& Barbière 2003). In the literature, numerous eutrophication indicators are described, varying from one region to the next and using different thresholds. Existing indices linked to eutrophication can be classified into 3 main groups: trophic indices, eutrophication indices and nutrientsensitivity (i.e. response to nutrient overenrichment) indices. Trophic indices generally include attempts to find a general empirical relationship between algal biomass or production and nutrient concentration or loading (de Jonge 1990, Nixon 1992, Moriki \& Karydis 1994). Some studies include surface oxygen content (Trophic Index [TRIX], Vollenweider et al. 1998) or Secchi depth (Organisation for Economic Co-operation and Development [OECD] classification, Zurlini 1996). Eutrophication indices are based on monitoring of biotic or/and abiotic parameters. All biotic indices take into account changes in the phytoplankton community (Tsirtsis \& Karydis 1998, Danilov \& Ekelund 2001) or the benthic community (Grall et al. 1997) accompanying eutrophication. Abiotic eutrophication indices use data on nutrient concentration and near-bottom oxygen concentrations (Abdullah \& Danielsen 1992), or surface and bottom dissolved oxygen levels (Justic 1991). Nutrient-sensitivity indices are based on the dilution and flushing capacity of estuaries (NOAA indices DCP [dissolved concentration potential] and EXP [estuarine export potential] [NRC 2000] tidal index [Monbet 1992]) or light and nutrient limitations for phytoplankton growth (Cloern 1999). An index combining physical vulnerability, pelagic and benthic characteristics and trophodynamics was successfully tested for 5 estuaries by Ferreira (2000). However, these indices are either region-specific (biotic criteria) or incomplete (physical sensitivity), and all are geographically restricted (i.e. applied on the scale of a bay or an estuary) because of the necessary input of in situ measurement at appropriate intervals.
The implementation of policies is dependent on the capacity of ecological indicators to capture the complexities of the ecosystem yet remain simple enough to be easily and routinely monitored (Dale \& Beyeler 2001). An urgent need for a standardisation of criteria and indices on a European scale and on a basin scale is recognised by the scientific community and responsible authorities in order to compare the status and trends of eutrophication (Cognetti 2001). In this paper, synoptic indices describing the eutrophication status of European shallow seas and their physical vulnerability are presented. The physically sensitive area index to eutrophication (PSA) emphasises the key role of hydromorphology in the assimilative capacity of shallow ecosystems which may face an increased load of nutrients. The eutrophication risk index (EUTRISK) represents the most probable oxygen-deficiency distribution near the bottom. The EUTRISK index includes biological (organic load) and physical (oxygen reserve and renewal) pressures near the seabed. PSA and EUTRISK offer a synoptic and comparable analysis of shallow marine eutrophication. Natural physical vulnerability enables us to evaluate the relative contribution of abiotic factors on eutrophication. The methodology uses relatively new observation and modelling tools which allow investigation on a large scale. For the first application we chose 2 test areas with highly diverse physical regimes, the Adriatic Sea and the North Sea area (Fig. 1).

\section{DATA AND METHODOLOGY}

Concept of eutrophication. The simplified concept of eutrophication adopted for the indices aims at being applicable on a large scale to any shallow coastal sea. It considers main pressure, effect, impact and supporting factors. A high nutrient concentration induces a high level of primary production. Particulate organic matter (POM) sinks to the sediments especially in shallow waters and, in turn, leads to oxygen consumption near the bottom, and in extreme cases, depletion. Hypoxia is one of the most common impacts of humaninduced marine eutrophication worldwide, and has expanded rapidly during the last 3 decades (see overviews of coastal marine hypoxia in Diaz \& Rosenberg 1995 and Diaz 2001). However, ecosystem responses to nutrient enrichment lead to various alterations in the food-web structure, often with a concomitant decrease in its complexity and a loss of species diversity, with an increase in opportunistic species (Skei et al. 2000). Diatoms decrease in relative importance, while summer blooms of inedible algae (e.g. Phaeocystis spp., toxic dinoflagellates, toxic prymnesiophyceaens) prevail (Sommer et al. 2002). The increasingly successful 

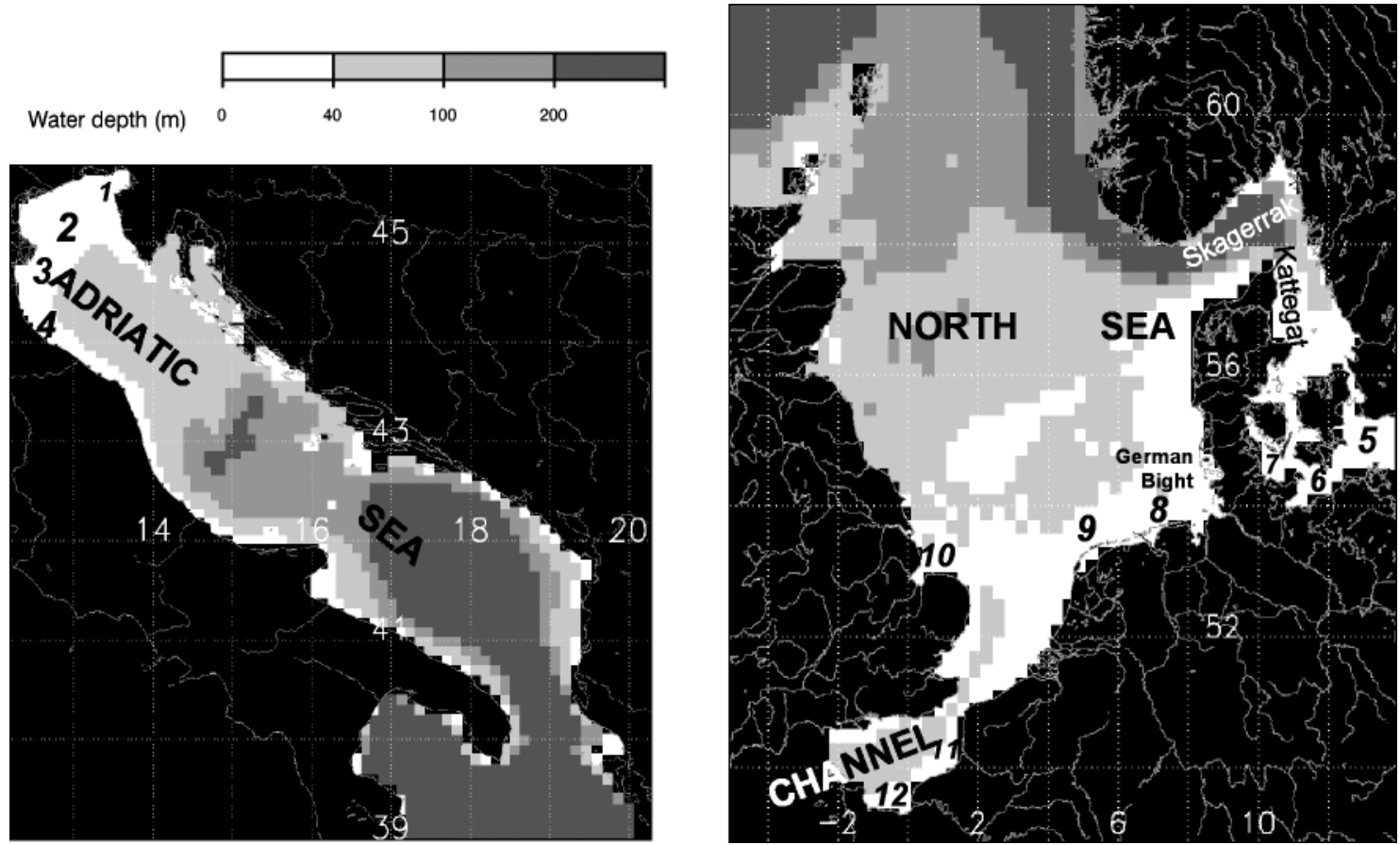

Fig. 1. Water depth in the Adriatic and North Seas given by the hydrodynamical models and location of Bay of Trieste (1), Venice Gulf (2), Po river mouth (3), Emilia-Romagna coast (4), western Baltic Sea (5), Mecklenburg Bay (6), Kiel Bay (7), German (8) and Dutch (9) Wadden Sea, Wash embayment (10), Bay of Somme (11), and Bay of Seine (12). Black areas are either land or sea areas not covered by the models

exploitation of changing coastal waters by one of these opportunistic groups, the dinoflagellates, is probably favoured by their adaptable ecology; dinoflagellates, (in contrast to diatoms) are habitat specialists, have multiple life-form strategies and behave as bloom soloists (Smayda \& Reynolds 2003). Therefore, to some degree, the diversity of ecological effects of eutrophication had to be included in the conceptual model described in this paper. As they are persistently subjected to episodic events, continental shelves generally favour export rather than retention food chains (Wassmann 1998). Eutrophication amplifies this phenomenon in the boreal coastal zone of the North Atlantic, where the ratio export production to aphotic zone:total production was found to increase with increasing trophic level in the range 60 to $230 \mathrm{~g} \mathrm{C} \mathrm{m}^{-2} \mathrm{yr}^{-1}$ (Wassmann 1990). Riegman (1995) suggested that the downward transport of organic matter to the sediments is favoured by eutrophication not only through higher algal biomasses but also as a consequence of a shift towards larger algal species with higher sedimentation characteristics. In parallel, the rapid changes in species composition that occur when the dynamic balance of consumer and resource control is distorted (Worm et al. 2002) increase selective grazing (Riegman 1995, Sommer et al. 2002) and reduce the role of grazers.
Finally, the changes in phytoplankton biomass and production that result from nutrient enrichment and shift of phytoplankton community are widely detected at the appropriate frequency by satellite-derived chlorophyll a measurements, despite the limitations discussed in this paper. Although in situ monitoring by traditional means is more accurate and complete, it has a very limited spatio-temporal coverage. In contrast, the frequent observation of chlorophyll-like pigments of coastal seas by optical remote-sensing provides a good estimate of the main mechanism driving eutrophication. At present, for the scales investigated, a better assessment of POM production is obtained using satellite-derived chlorophyll a measurements rather than a full bio-physical modelling approach. In fact, the strategy presented herein avoids the uncertainties linked with the largely unknown distribution of nutrients, their respective ratios and the associated phytoplankton dynamics (light availability, growth rate and nutrient uptake). The EUTRISK index does not require knowledge of nutrient nor phytoplankton dynamics as it uses a satellite-derived estimate of primary production. In the EUTRISK index, moderate hypoxia and/or food-web alterations represent together an intermediate step in eutrophication. The trophic classification used hereafter is Nixon's (in $\mathrm{g} \mathrm{C} \mathrm{m}^{-2} \mathrm{yr}^{-1}$ ): $<100=$ oligo- 
trophic, 100 to $300=$ mesotrophic, 300 to $500=$ eutrophic and $>500=$ hypertrophic (Nixon 1995).

The supporting factors expressed by the PSA index comprise the physical characteristics of the surface and bottom-layer which, respectively, play key roles in phytoplankton growth and oxygen renewal near the sea bottom. The PSA index stresses the main physical conditions that influence the formation and fate of organic matter of phytoplankton origin. The PSA index includes strictly hydromorphological characteristics and therefore assumes that nutrients are not limiting primary production. Presuming that the oxygen renewal is mainly controlled by hydrodynamics, the oxygen budget formulated in the EUTRISK index utilises the physical characteristics near the sea bottom as the source term and the organic load reaching the seabed as the sink term. The basic principles of the PSA and EUTRISK indices are to use known, deductible or easily observable and non-correlated parameters with adequate temporal and spatial resolution.

Numerical model data. Both models used for the Adriatic Sea (ISPRAMIX) and the North Sea (HAMSOM) are 3D baroclinic circulation, free-surface, hydrostatic models, which have prognostic equations for velocity, temperature, salinity and turbulent kinetic energy.

The ISPRAMIX model was applied and validated for general circulation in the Atlantic by Demirov et al. (1998) and in the Adriatic Sea (coupled with an atmospheric model) by Dobricic (2002). For the latter area, the model was also applied together with a 4D dataassimilation technique by Garcia-Gorriz et al. (2003). The grid size for the application to Adriatic Sea is $85 \times$ 85 cells ( 39.0 to $45.8^{\circ} \mathrm{N}, 12.2$ to $20.3^{\circ} \mathrm{E}$ ). The horizontal resolution is about $4 \mathrm{~km}$ in the northwest (corresponding to shallow waters) and $10 \mathrm{~km}$ in the southeast of the basin. The model uses a $z$-coordinate with a maximum of 40 vertical levels. In the first $100 \mathrm{~m}$ the model has 20 layers, with the resolution varying from $2 \mathrm{~m}$ near the surface to $12 \mathrm{~m}$ at $100 \mathrm{~m}$ depth.

The Hamburg Shelf Ocean Model (HAMSOM), developed jointly by the Institut für Meereskunde (Hamburg University) and Clima Maritimo (Madrid), is used for the North Sea. The model was described and validated in this area by Pohlmann (1996). The grid size for this application is $58 \times 65$ cells ( 48.9 to $61.7^{\circ} \mathrm{N}$, $5.1^{\circ} \mathrm{W}$ to $13.9^{\circ} \mathrm{E}$ ). The horizontal resolution is $20 \mathrm{~km}$. The model uses the $z$-coordinate with a maximum of 19 vertical levels. The layer thickness is $5 \mathrm{~m}$ for the first $50 \mathrm{~m}$, and 10, 15 and 25 to $100 \mathrm{~m}$ depth (at 60, 75 and $100 \mathrm{~m}$, respectively), with steadily increasing resolution for deeper water.

Besides water depth, the physical parameters required for the indices are monthly means based on climatology or at least 5 yr monthly means of: maximum of the vertical density gradient estimated from mean daily profiles, depth of the mixed layer corresponding to the maximum of the density gradient, mean current velocity of the mixed layer ( $x$ and $y$ components) or residual current in case of a tidal system, and mean turbulent diffusion coefficient near the bottom.

For the HAMSOM model, the thickness of the last layer is not strictly identical for cells of depth greater than $50 \mathrm{~m}$ and the bathymetry is approximated in proportion to the coarse resolution. Hence, the value of the turbulent diffusion coefficient might be affected on a pixel basis, although the regional levels are correctly reproduced. In the Adriatic Sea area, the ISPRAMIX model utilises a parameterisation of bottom-mixing (Eifler 1993), which prevents the diffusion coefficient being dependent on layer thickness. The momentum calculation assumes the existence of a viscous layer, a few millimetres thick, above which the velocity has a logarithmic profile. The viscous layer becomes important when bottom velocity is low and vertical mixing is mainly due to molecular viscosity.

The results presented in this paper are 1991 to 1998 means for the Adriatic Sea and 1982 to 1998 means for the North Sea.

Remote-sensing data. Satellite chlorophyll a from SeaWiFS (seawide field-of-view sensor) is estimated using atmospheric corrections developed at the Joint Research Centre (JRC) Ispra (Sturm \& Zibordi 2002), and the Ocean Colour 5 algorithm (OC5: Gohin et al. 2002). The atmospheric correction scheme produces satisfactory normalised water-surface radiances (generally the difference between the satellite-derived and in situ 490:555 $\mathrm{nm}$ ratios is $<10 \%$ ) for a wide range of atmospheric and geometric conditions. The OC5 chlorophyll a algorithm uses 5 channels (412, 443, 490, 510 and $555 \mathrm{~nm}$ ) to correct for the effect of the total suspended matter that affects atmospheric correction (marine-origin contribution in near infrared region). The latter is responsible for large over-estimation of chlorophyll a concentration when using the standard Ocean Colour 2 algorithm designed for oceanic waters (OC2: O'Reilly et al. 1998). The OC5 algorithm was validated for the turbid waters of the English Channel and French Atlantic waters. The root mean-square error (RMS) between estimated and measured chlorophyll $a$ is 0.9 , and the $r^{2}$ coefficient of the linear regression is 0.7 for log-transformed data. The OC5 algorithm was re-calibrated with respect to the water-surface radiances obtained with the JRC atmospheric corrections, using the same data set as in Gohin et al. (2002). Although such an empirical approach outside the validation area slightly increases the overall error, the application of the OC5 algorithm to suspended matterdominated systems such as the North Sea and the northern Adriatic Sea leads (in comparison to oceanic 
algorithms) to an improvement in the chlorophyll a estimation. Nevertheless, uncertainties are limited because of efficient correction of the atmospheric component and the limited extent of turbid waters during the period of major interest for the EUTRISK index (summer). The large chlorophyll a overestimation due to suspended sediments using the oceanic-aimed NASA algorithm is avoided by using the OC5 algorithm. Because satellite-derived chlorophyll $a$ is reasonably well estimated in turbid waters, the effect of turbidity on primary production is therefore implicitly taken into account (low biomass level) and turbidity is therefore not explicitly included in the EUTRISK methodology. A complete coverage of the considered areas by satellite observations in spring and summer for 1998, 1999 and 2000 is assured by use of the monthly mean composites.

Indices. Choice and importance of water depth: The term 'shallow waters' in this paper applies to water depths between ca. 5 and $100 \mathrm{~m}$, the term 'deep water' to water deeper than $100 \mathrm{~m}$. The shallower limit ( 5 m) depends on the integration depth of the ocean colour sensor and the resolution of the numerical model. For deep water, the indices are not calculated because anoxia mainly results from permanent stratification. Deep-water hypoxia or anoxia are assumed, in a first approximation, not to arise from anthropogenic activity. Deeper than $100 \mathrm{~m}$, remineralisation of the organic matter in the water column is sufficient to prevent any important oxygen deficiency near the sea bottom in the absence of a permanent stratification. A minimum remineralisation rate of detrital organic matter during the growing season (at 15 to $20^{\circ} \mathrm{C}$ ) of $0.075 \mathrm{~d}^{-1}$ (Ménesguen \& Hoch 1997, Druon \& Le Fèvre 1999), associated with a maximum sinking velocity of senescent and actively growing phytoplankton cells of ca. $8 \mathrm{~m} \mathrm{~d}^{-1}$ (Fortier et al. 1994), leads to a rate of $7 \%$ surface biomass deposition at $100 \mathrm{~m}$. Even when diatom aggregates are more efficient, and export organic matter at a sinking velocity of from 50 to $200 \mathrm{~m} \mathrm{~d}^{-1}$ (Alldredge \& Gotschalk 1989), this mode of transport, while possibly important as a source of organic material for deep waters, always involves less than $1 \%$ of the ultraphytoplankton in the euphotic zone (Silver et al. 1987). Accordingly, no severe oxygen deficiency or depletion arising from anthropogenic sources (i.e. from terrestrial input of nutrients) occurs at the deep-sea bottom. Sill basins or sill deep fjords, as in the Baltic Proper or some Norwegian or west
Canadian fjords, are anoxic principally because of restricted deep-water renewal associated with permanent stratification. In such cases, hydromorphological conditions play a major role in isolating water masses that subsequently become sensitive to eutrophication. A surplus of organic matter of anthropogenic origin reinforces the low oxygen milieu of these deep waters, but the original main cause is poor water-exchange. PSA and EUTRISK are aimed at detecting and quantifying, on a comparable scale, human-linked eutrophication to provide guidance for restoration. Hence, the focus is on coastal waters shallower than $100 \mathrm{~m}$.

The overall concept of the PSA and EUTRISK indices is based on the accumulation of favourable or adverse effects for eutrophication, expressed as comparable and dimensionless indices between 0 and 1 . All basic parameters identified in this paper are considered to be critical for marine eutrophication, and consequently the derived sub-indices are weighted at 1 .

PSA index: The aim of the PSA index is to assess the capacity of the physical environment to modify the production and assimilation of organic matter in shallow marine ecosystems. The PSA index (Fig. 2) assumes that nutrients are evenly distributed and

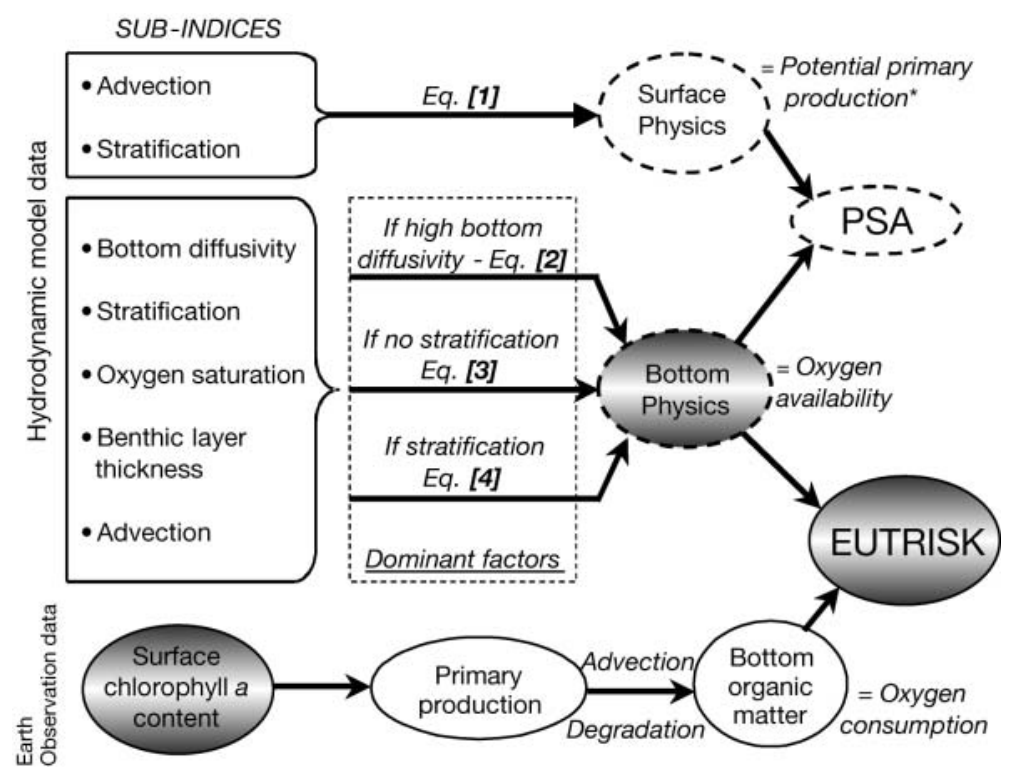

Fig. 2. Conceptual model of coastal eutrophication indices: the physically sensitive area (PSA) index (dashed lines) and the eutrophication risk (EUTRISK) index (shaded area). The PSA index integrates the various supporting factors of eutrophication, i.e. the physical conditions that influence primary production in the upper layer and oxygen availability near the sea bottom; $^{*}$ : surface physical index represents potential primary production, as nutrients are assumed to be evenly distributed and not limiting. EUTRISK characterises the spatial distribution of potential hypoxia integrating oxygen availability near the bottom and the flux of organic matter reaching the seabed. Following the principle of the dominant factor, the bottom physical index (C_phys_bott) uses 3 different equations (see Eqs. 2, 3 \& 4) depending on the level of bottom-diffusivity and stratification (see 'Data and methodology' for details) 
available in the surface layer. Hence it indicates, indirectly and on a relative scale when comparing shallow seas, the maximum assimilative capacity of the ecosystem, taking into account the dispersal capacity of the environment (vertical mixing and transport) and morphology of the area. It provides a comparable measure of physical resistance to eutrophication on a simple scale (value from 0 [= blue, high resistance] to 1 [= red, low resistance]) for shallow European seas. The main assumption of this index is that phytoplankton growth and the oxygen cycle near the sea bottom are largely conditioned by local physical conditions (surface and bottom-layer characteristics respectively). Identical discharge of nutrients into shallow stratified waters where advection and the bottomdiffusivity are low, or into a tidal (or deep) system will have different impacts. The various shallow marine ecosystems in European regions and worldwide have a strongly disparate physical resistance to eutrophication that must be assessed in order to appraise restoration possibilities.

A limited set of physical parameters available from numerical modelling was identified to describe the surface and bottom physical characteristics (Fig. 2). Advection and stratification define the surface characteristics, i.e. favourable hydromorphological conditions for phytoplankton growth. Advection represents the horizontal transport and diffusion of nutrients from a point source and acts as an export and dilution factor; stratification, by retaining phytoplankton cells in the euphotic zone, increases the relative light available for photosynthesis. Bottom-diffusivity, stratification and advection are used to characterise vertical and horizontal oxygen renewal capacities near the sea bottom. The first effect of well-established stratification on coastal eutrophication is increased primary production in areas where the surface layer is supplied with nutrients, i.e. mainly areas influenced by freshwater input. In offshore areas, where the surface layer does not receive nutrient supplies from horizontal transport, stratification tends to hamper phytoplanktonic production by reducing vertical supply from the nutrientrich deeper layer, and therefore tends to counteract eutrophication. Because indices describing physical vulnerability to eutrophication are strictly hydromorphological, not chemical, the methodology presumes an even nutrient distribution. Consequently, stratification is considered only as a factor favouring primary production, and focus is therefore given to areas where the surface layer receives a nutrient supply, i.e. the main eutrophication hot-spots. Stratification, as a second effect, reduces the capacity to regenerate the deeperlayer oxygen. In contrast, bottom-diffusivity increases vertical mixing and prevents severe oxygen deficiencies. The dynamic representation of the oxygen cycle near the bottom is completed by an estimate of the oxygen reserve. The latter depends on the degree of oxygen saturation (i.e. on salinity and temperature) and on the water mass between the mixed layer and the sea bottom in those cases where turbulence and eddy diffusion provide enough energy to mix the dissolved materials within the benthic layer.

Each physical variable is characterised by an index (dimensionless, between 0 and 1 ) with a maximum and minimum threshold. The range defined is considered to be linear, and is assumed to cover any variability that influences the process considered (e.g. the influence of stratified or extremely stratified waters on primary production). An index value close to zero (blue) represents high resistance to eutrophication, and a value close to 1 (red) low resistance. The general forms of the indices are (except for benthic layer thickness index, C_blt, see equations below):

$$
\text { C_ } i_{x, y, t}=\left(\frac{\text { Value_ } i_{X, Y, t}-\text { Thres_min_i }}{\text { Thres_max_i } \_ \text {Thres_min_i }}\right) \leq 1
$$

for stratification index, C_strat (unfavourable process) and

$$
\text { C_ } i_{X, Y, t}=\left(1-\frac{\text { Value } \_i_{x, y, t}-\text { Thres_min_ } i}{\text { Thres_max_i }- \text { Thres_min_i }}\right) \leq 1
$$

for bottom-diffusivity (C_kz_b), mixed-layer advection (C_adv) and oxygen-saturation (C_oxy_sat) indices (favourable processes), where $C_{-} i$ is the index of Variable $i$, Value_ $i$ is its value, Thres_max_ $i$ and Thres_min_ $i$ are the corresponding maximum and minimum thresholds, $x, y$ refer to the model grid, and $t$ to the monthly time step. Table 1 presents the threshold values for each physical variable used in deriving the indices, and Fig. 3 compares the monthly spatial (water depths shallower than $100 \mathrm{~m}$ ) means of the selected parameters for the North and the Adriatic Seas. Similar scales were chosen to better analyse the differences between

Table 1. Selected physical parameters and corresponding threshold values

\begin{tabular}{|llccc|}
\hline \multirow{2}{*}{ Parameter } & Description & Threshold values & Unit \\
& & Min. & Max. & \\
\hline adv & Advection $(u, v)$ & 0 & 0.10 & $\mathrm{~m} \mathrm{~s}^{-1}$ \\
strat & Stratification intensity $\frac{\Delta \rho}{\Delta z}$ & 0 & 0.05 & $\mathrm{~kg} \mathrm{~m}^{-4}$ \\
kz_b & $\begin{array}{l}\text { Turbulent diffusion coefficient } \\
\text { at the bottom }\end{array}$ & 0 & 0.01 & $\mathrm{~m}^{2} \mathrm{~s}^{-1}$ \\
oxy_sat & $\begin{array}{l}\text { Oxygen saturation } \\
\text { maximum for } \mathrm{S}=5 \mathrm{psu} \text { and } T=8^{\circ} \mathrm{C}\end{array}$ & & & \\
& minimum for $\mathrm{S}=38 \mathrm{psu}$ and $T=22^{\circ} \mathrm{C}$ & 6.99 & 11.45 & $\mathrm{mg} \mathrm{l}^{-1}$ \\
\hline
\end{tabular}


Fig. 3. Monthly and spatial means (continuous lines) and standard deviations (dashed lines) for selected physical variables in the Adriatic Sea (left-hand panels) and the North Sea (righthand panels) for waters shallower than $100 \mathrm{~m}$. (a) Mean advection of mixed layer or residual current in case of tides (b) maximum vertical density gradient estimated from mean daily profiles; and (c) mean diffusivity coefficient near sea floor
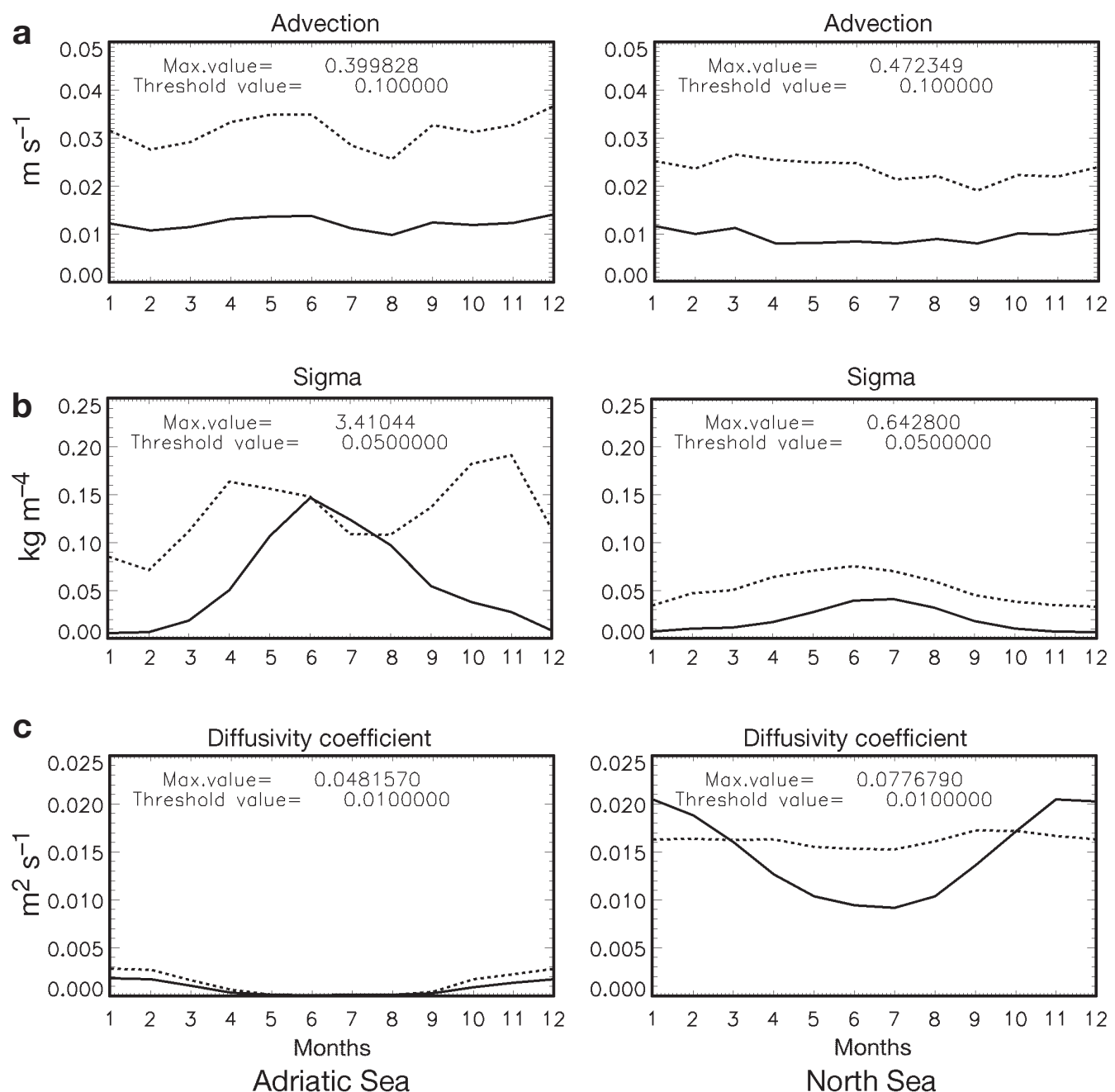

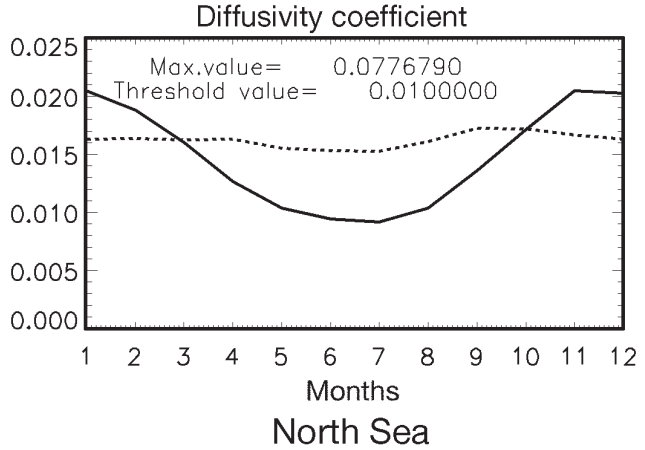

the 2 physical environments. The intensity of the mixed-layer advection (or residual current for the tidal system) is similar in both seas, with low variability. However, there is a higher standard deviation in the Adriatic Sea, with 2 maxima in spring and autumn and a critical minimum for eutrophication in summer. The monthly mean residual current in the North Sea is, in some respects, constant due to its tidal regime; however, variability in the neap-spring tide does not occur on a monthly scale. As shown in Fig. 3a, no major temporal variability in advection is observed, but important spatial variability occurs. During the most critical months for eutrophication, i.e. in summer, surface advection of the Adriatic Sea is dominated by 3 anticyclonic gyres in the south, central and north of the basin. The advection minima $\left(<0.01 \mathrm{~m} \mathrm{~s}^{-1}\right)$ are encountered in the gyre centres and the Bay of Trieste area, and a relatively low surface advection $\left(<0.05 \mathrm{~m} \mathrm{~s}^{-1}\right)$ characterises the entire northern Adriatic Sea north of $45^{\circ} \mathrm{N}$. In contrast, surface advection is particularly strong in the shallow waters facing the Po river mouth and further south along the Emilia-Romagna coast ( $>0.1 \mathrm{~m} \mathrm{~s}^{-1}$ monthly mean). Similar maxima of surface advection or residual current are encountered in the Skagerrak and in a few straits of the Kattegat, but most of the North Sea is dominated by low residual currents $\left(<0.01 \mathrm{~m} \mathrm{~s}^{-1}\right)$.

As a consequence of the 2 different (meteorological and tidal) regimes, stratification and bottom-diffusivity show large differences between the 2 areas. The wellstratified waters of the Adriatic Sea in spring and summer contrast with the relatively highly mixed waters of the North Sea in the same period. The tidal-induced bottom-diffusivity in the North Sea is globally inversely correlated with water depth, except for the Kattegat, where the tide is low. In the Adriatic Sea, the intensity of bottom-diffusivity is comparatively 10- to 20-fold lower (Fig. 3c), even in the northern shallow waters, where a high level of surface advection is observed. In this case, stratification isolates the bottom layer from the wind and density currents. Bottomdiffusivity is more intense (ca. 2-fold) during the winter 
months in both areas. However, in the North Sea area, the regional level (data not shown) dominates seasonal variability, with permanently high values of bottomdiffusivity in tidal areas, (i.e. southern North Sea and English Channel) and permanently low values in the central and northern North Sea, the Skagerrak, the Kattegat and Belt Seas. Relatively to the North Sea area, the Adriatic Sea displays low and homogeneous bottom friction; its thermohaline stratification displays high spatial and temporal variability. For most areas in both basins, stratification is a seasonal phenomenon (summer thermocline). However, its extension and duration in the tidal area of the North Sea depends mainly on the intensity of bottom-diffusivity. In contrast, a quasi-permanent halocline occurs in the major part of the Skagerrak, Kattegat, Belt Seas and along the Emilia-Romagna coast due to the continuous input of fresh water from the Baltic Sea and the Po river, respectively. In areas of shallow bathymetry, these permanent features dramatically increase the sensitivity of these areas to eutrophication by isolating the bottom layer from the vertical supply of oxygen.

The oxygen saturation concentration depends on temperature and salinity. As it can vary from warm-salty to cold-fresh systems, the oxygen saturation index is of importance in estimating oxygen reserves near the seabed. It uses the monthly mean temperature and salinity at the sea floor calculated by the models:

C_oxy_sat ${ }_{x, y, t}=\left(1-\frac{\text { oxy_sat }_{x, y, t}-\text { Thres_min_oxy_sat }}{\text { Thres_max_oxy_sat }- \text { Thres_min_oxy_sat }}\right) \leq 1$ where oxy_sat is the oxygen saturation given by Weiss (1970) as:

$$
\begin{aligned}
\text { oxy_sat } & =\mathrm{C} 1 \times \exp \left\{\mathrm{A} 1+\mathrm{A} 2 \times \frac{100}{T}+\mathrm{A} 3 \times \ln \left(\frac{T}{100}\right)+\mathrm{A} 4 \times \frac{T}{100}\right. \\
& \left.+S \times\left[\mathrm{B} 1+\mathrm{B} 2 \times \frac{T}{100}+\mathrm{B} 3 \times\left(\frac{T}{100}\right)^{2}\right]\right\}
\end{aligned}
$$

where $\mathrm{A} 1=-173.4292, \mathrm{~A} 2=249.6339, \mathrm{~A} 3=143.3483$, $\mathrm{A} 4=-21.8492, \mathrm{~B} 1=-0.033096, \mathrm{~B} 2=0.014259, \mathrm{~B} 3=$ $-0.001700, \mathrm{C} 1=1.4276\left(\mathrm{mg} \mathrm{l}^{-1}\right)$ or $\mathrm{C} 1=1 .\left(\mathrm{ml} \mathrm{l}^{-1}\right)$, where $T$ is temperature, degrees Kelvin $\left(T^{\circ} \mathrm{C}+273.15, S\right)$ is salinity (psu), Thres_max_oxy_sat is the maximum saturation for $S=5 \mathrm{psu}$ and $T=8^{\circ} \mathrm{C}$ and Thres_min_oxy_sat is the minimum saturation for $S=38 \mathrm{psu}$ and $T=22^{\circ} \mathrm{C}$, leading to values of 11.45 and $6.99 \mathrm{mg} \mathrm{l}^{-1}$, respectively (see Table 1). The distribution of C_oxy_sat for both seas shows a general higher oxygen reserve in the North Sea due to lower temperature and salinity. The higher saturation encountered in eastern Danish waters due to low salinity decreases from spring to summer with increasing temperature, but remains at a medium value (C_oxy_sat 0.6 ). The lowest saturation levels of bottom waters (C_oxy_sat $~ 0.9$ ), and therefore the most critical areas in terms of oxygen reserve, are encountered during summer in the SE North Sea, in the English Channel and in the shallow waters of the Adriatic Sea, and all correspond to the temperature maxima.

The other index representative of oxygen reserves in stratified waters is the benthic layer thickness index, C_blt, which uses, as a critical parameter for eutrophication, the thickness of the layer below stratification. The absence of turbulent diffusion at the sea bottom would be very critical, as the benthic boundary layer (and the correspondent oxygen availability) would decrease down to a thin diffusive boundary layer, approximately $1 \mathrm{~mm}$ thick, through which molecular diffusion is the dominant transport mechanism for dissolved materials (Gundersen \& Jørgensen 1990). Even though very strong oxygen gradients have been reported near the bottom (from 6.0 to $0.4 \mathrm{mg} \mathrm{l}^{-1}$ for the deepest $0.5 \mathrm{~m}$ in the Limfjord, Denmark: Jørgensen 1980), most of the time, eddy diffusion provides sufficient energy to increase the benthic boundary layer significantly. The C_blt index calculation presumes that enough bottom turbulence is provided to mix the entire layer below the mixed layer (i.e. that the oxygen in that layer is available). This index represents the potential oxygen reserve of the benthic layer independent of bottom turbulence. The bottom-diffusivity index, C_kz_b, is used in conjunction with the C_blt index to modulate the effect of various levels of turbulence in the calculation of the index of the bottom physical characteristics. The empirical relationship linking C_blt and the depth difference between the sea bottom and the pycnocline $(H b)$ is a polynomial equation decreasing from a value of 1 for $H b=0-8 \mathrm{~m}$ to 0 for $H b=35 \mathrm{~m}$ :

$$
\begin{aligned}
\text { C_blt }_{X, Y, t} & =5 \times 10^{-5} \times H b_{x, y, t}{ }^{3}-3.2 \times 10^{-3} \\
& \times H b_{x, y, t}{ }^{2}+1.99 \times H b_{x, y, t}+0.9901
\end{aligned}
$$

The dissolved oxygen (DO) profiles for benthic layers deeper than 30 to $40 \mathrm{~m}$ indicate that DO is not a limiting factor for oxygen reserves in these layers. Oxygen depletion becomes critical when the benthic layer is only few metres deep. Therefore, a stratified water column 15 to $30 \mathrm{~m}$ deep is particularly susceptible to oxygen deficiency, and this corresponds to the depth stratum where oxygen depletion is mostly observed (see 'Discussion'). The distribution of C_blt in August emphasises the critical role of volumetric oxygen reserves in stratified shallow waters, i.e. in the northern Adriatic Sea and along the eastern Italian coast, the central North Sea, the Kattegat and the western Baltic Sea.

The index of bottom physical characteristics (C_phys_ bott), which represents oxygen availability, is calculated using the dominant-factor principle (see Fig. 2). 
High bottom-diffusivity (see Eq. 2, below) is a dominant physical factor which efficiently protects the ecosystem from anoxia. The tidal-enriched system of the Bay of Seine in France is eutrophic (Cugier 1999), with high chlorophyll concentrations (up to 60-70 $\mathrm{mg} \mathrm{m}^{-3}$ ) from spring to autumn (Aminot et al. 1997), but buoys continuously measuring oxygen concentration do not show near-bottom oxygen saturation below $65 \%$, which corresponds to $5.0 \mathrm{mg} \mathrm{l}^{-1}$ for the salinity and temperature considered (MAREL data for 1998-1999; available at www.ifremer.fr/marel/). In the case of low levels of bottom-diffusivity and stratified waters (see Eq. 4, below), the thickness of the layer below the pycnocline limits the quantity of available oxygen. The deepening of the mixed layer in shallow waters in summer and autumn, which also corresponds to a temperature maximum and thus to lower oxygensaturation levels, leads to a critical decrease in the oxygen reserve near the sea bottom. When the water column is not stratified with a relatively low bottomdiffusivity (see Eq. 3, below), advection (of the water column or the first $100 \mathrm{~m}$ ) is an important physical process whereby oxygen can be supplied horizontally. Taking the above into consideration, the equations for the surface and bottom physical indices are (see also Fig. 2):

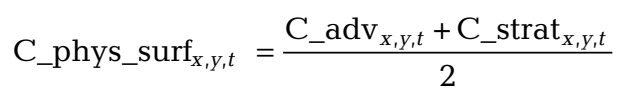

If $\mathrm{C} \_\mathrm{kz} \_\mathrm{b}<0.1$ (high bottom-diffusivity):

$$
\text { C_phys_bott } x_{x, y, t}=\text { C_kz_b } \mathrm{b}_{X, Y, t}
$$

If C_kz_b $>0.1$ and C_strat $<0.1$ (lower bottomdiffusivity without stratification):

$$
\begin{aligned}
& \text { C_phys_bott } \\
& \underline{\text { C_k kz_t, }}= \\
&
\end{aligned}
$$

If C_kz_b > 0.1 and C_strat > 0.1 (lower bottomdiffusivity with stratification):

$$
\begin{aligned}
& \text { C_phys_bott }{ }_{x, y, t}= \\
& \frac{\text { C_kz_b b }{ }_{X, Y, t}+\text { C_oxy_sat }}{x, y, t}+\text { C_strat }{ }_{X, Y, t}+\text { C_blt } \\
& 4
\end{aligned}
$$

The monthly PSA formulation is a mean of the surface and bottom physical indices for shallow waters:

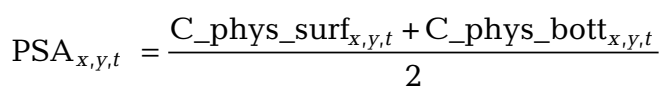

This simple arithmetic approach was chosen to reflect the priorities of the physical factors regulating eutrophication and to facilitate analysis of the results.
EUTRISK index: The EUTRISK index characterises the most probable occurrence of oxygen deficiency at the bottom in shallow-sea areas due to degradation of particulate organic matter (POM), taking into account oxygen availability. SeaWiFS data are used to estimate phytoplankton primary production and numerical modelling provides data on the physical capacity to store and renew sea-bottom oxygen (i.e. the bottom physical factors defined above).

Where the water depth favours pelagic primary producers, phytoplankton is the main source of production and export of organic matter to the seabed. The other contributors to sedimentation at a higher trophic level are mainly micro- and mesozooplankton. Besides the effect of selective grazing in eutrophicated waters already discussed, mesozooplankton is quantitatively of second-order importance in terms of downward transport of organic matter in shallow waters (less than $100 \mathrm{~m}$ ) because its export efficiency (high sinking velocities) decreases compared to phytoplankton and microbial export. During the growing season, mesozooplankton faecal pellets contributed on average less than $5 \%$ of the total carbon flux at a $29 \mathrm{~m}$ depth station in SE Kattegat (Olesen \& Lundsgaard 1995). The relatively high sinking velocity used for POM sedimentation (5 $\mathrm{m} \mathrm{d}^{-1}$, Fortier et al. 1994) includes the aggregation of detritus particles produced in the microbial food web (pico-, nano- and microzooplankton), which may represent the major contribution in shallow waters (Lundsgaard \& Olesen 1997).

Primary production inside the euphotic zone $(\Pi)$ is estimated by the expression of Eppley et al. (1985) using satellite-derived chlorophyll a (Chla_sat) values, and (with a lower correlation) day length (DL) and a temperature anomaly (PTA): $\ln \Pi=3.06+0.5 \times$ $\ln ($ Chla-sat $)-0.24 \times$ PTA $+0.25 \times$ DL. Focusing on the restricted August-September period for the EUTRISK index, seasonal variability in the second-order of importance parameters is ignored (DL and PTA are set as constants). A gross estimate of primary production variability (in relative units, Пrel) can therefore be assessed by the square root of the satellite-derived chlorophyll a concentration: $\Pi_{r e l_{X, Y} t}=$ $\sqrt{\text { Chla_sat_OC5 }{ }_{X, Y, t}}(X, Y$ refer to the SeaWiFS grid as opposed to $x, y$ for the model grid).

Because the production area does not necessarily correspond to the area where organic matter is exported to the seabed, an iterative transport procedure has been implemented. The monthly load of organic matter produced in the surface layer is exported horizontally within the mixed layer using the monthly mean advection provided by the respective model, and vertically using the constant sinking velocity $V s=5 \mathrm{~m} \mathrm{~d}^{-1}$. Between the mixed layer and the seabed, 
a linear decreasing horizontal velocity is used. With a time step that respects the maximum horizontal current velocity versus the smallest model resolution, the primary production estimate is transported horizontally using the closest current velocity of the model grid. A degradation rate of POM in the water column $\left(\tau_{\text {deg }}=0.075 \mathrm{~d}^{-1}\right)$ is applied to take into account the higher deposition rate in shallow waters compared to deeper waters. Once the organic matter has reached the bottom for a given month and for waters shallower than $100 \mathrm{~m}$, the distribution of POM is obtained by computing the summed organic matter (i.e. the primary production estimated for each satellite pixel) over the model grid. Accordingly, the POM flux index is defined as:

$$
\text { C_POM }{ }_{x, y, t}=\Pi r e l \_\exp _{x, y, t} \times \tau_{\text {depos }} \times C C
$$

where Пrel_exp is the monthly mean primary production exported to the sea bottom as a result of horizontal and vertical export calculated and summed over a model grid cell, $C C$ is a calibration constant $(C C=0.64)$ and $\tau_{\text {depos }}$ the deposition rate:

$$
\tau_{\operatorname{depos}(x, y)}=1-\left(\tau_{\text {deg }} / 86400\right) \times \frac{\text { depth_final }}{V S}
$$

where depth_final is the water depth at which the POM has reached the bottom.

The C_POM value represents the monthly oxygen demand at the sea bottom and, in contrast to the other indices, can exceed the value of 1 . In the conceptual model, the POM flux at the seabed expresses the driving force of eutrophication, as opposed to the hydromorphological conditions, which are supporting factors. Large organic loads to the sea bottom can be responsible for complete anoxia, and high C_POM values reflect those cases where oxygen demand may be higher than oxygen availability. The maximum value of C_POM for the Adriatic and North Seas is 2.72 and 1.48, respectively, for the year 2000.

In order to evaluate the risk of hypoxia, oxygen consumption is compared to the oxygen reserves and oxygen renewal during the growing season. During the spring-summer period, rising temperature reduces the oxygen reserves (lower saturation), stratification restricts oxygen renewal, and oxygen consumption increases due to the input of phytoplankton-derived organic matter. In fact, in most areas, there is a higher primary production during the spring bloom than during summer and autumn. However, despite a lower primary production, oxygen depletion or severe deficiencies occur in August and September, when the oxygen reserves and the renewal capacity of isolated water masses are lower.

The EUTRISK index provides an estimate of the lowest potential oxygen deficiency at the seabed, striking a balance between the monthly oxygen sink and availability (the index C_POM representing oxygen consumption and the C_phys_bott index representing oxygen reserves and renewal):

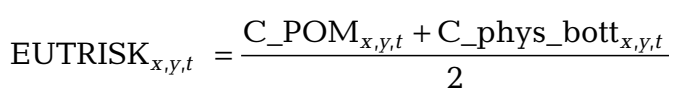

A risk assessment is performed because POM degradation and related oxygen consumption are processes occurring on a daily timescale that cannot be directly assessed with monthly mean data. Variability in physical conditions and primary production also occurs daily. Nevertheless, a few hours of oxygen depletion require a succession of events arising from reduced mixing on a longer timescale: stratification establishment, phytoplankton bloom, sinking of organic particles and their degradation are the main steps, on a daily timescale, that together require at least 2 or $3 \mathrm{wk}$ of calm weather. In order to generate an oxygen deficiency in the southern Kattegat-Belt Sea area between the end of June 2002 (end of an exceptional inflow of oxygenated marine water) and the last week of July (start of hypoxia)/mid-August 2002 (start of anoxia), 4 and 6 wk of bottom-water stagnation, calm winds and warm temperature were necessary (HELCOM 2003). During that event, an increase in biomass and primary production was observed between June and July 2002. The monthly mean data provide a satisfying first estimate of the biological and physical processes linked to eutrophication, but because the assessment is not made on a daily timescale, a risk assessment is proposed.

\section{RESULTS}

Fig. 4 presents the results for the index of the surface physical factors (C_phys_surf) for both coastal seas in April, August and December estimated from the advection and stratification characteristics of the surface layer. In others words, these maps show where phytoplankton growth would occur (high = red) if the nutrient supply in the top layer was uniformly distributed. In addition to showing the most favourable conditions in summer, mainly induced by stratification intensification, the seasonal cycle shows regional differences. The central zones of the basins or permanently stratified areas have physical conditions favourable for primary production (high values of C_phys_surf). In contrast, unfavourable conditions are located in strong tidal systems like the English Channel or in buoyancy currents like south of the Po river (low values of C_phys_surf). The nutrients present a strong regional distribution, however the C_phys_surf index emphasises different biological responses to the 
a
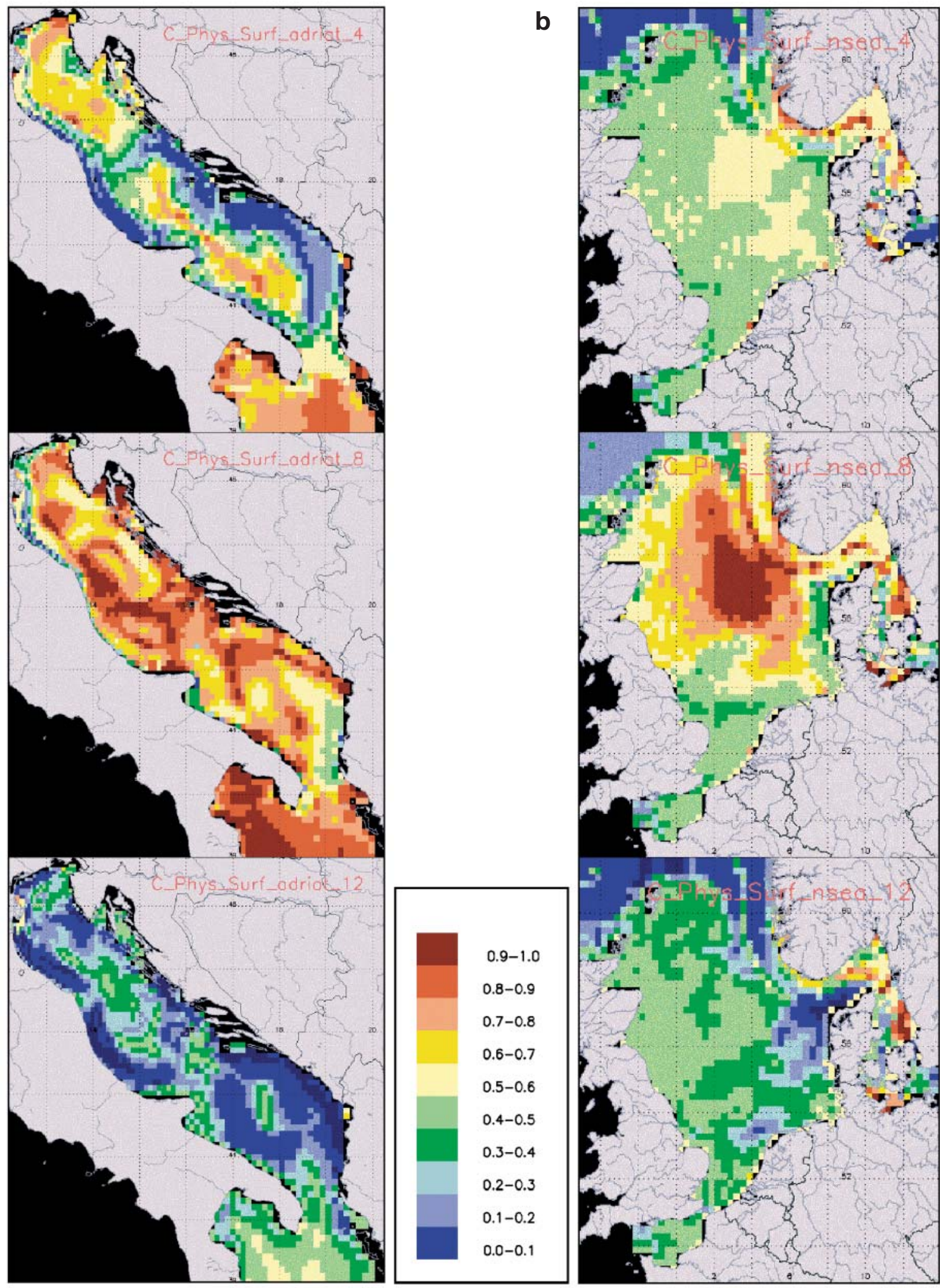

Fig. 4. Comparison of surface physics index, C_phys_surf, for (a) the Adriatic Sea and (b) the North Sea in April, August and December (from top to bottom, respectively). Index represents surface physical conditions favourable (high values $=$ red) $/$ unfavorable (low values = blue) for phytoplankton growth (assuming nutrients are not limiting). Regions south-west of Italy, west English Channel and west of UK areas are not covered by models 
a
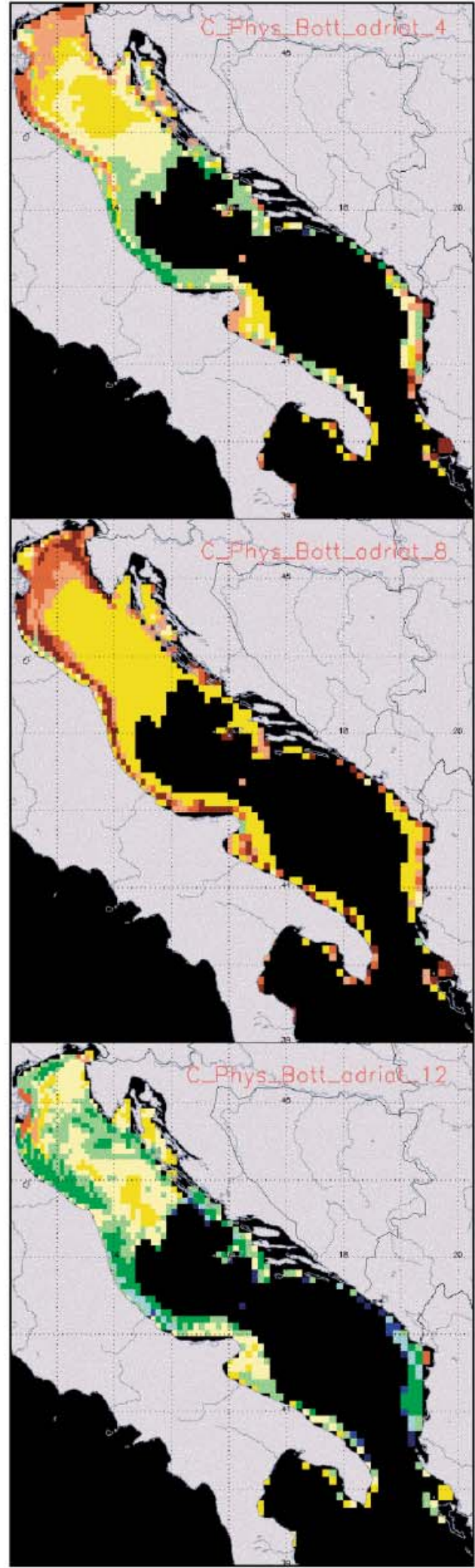

b

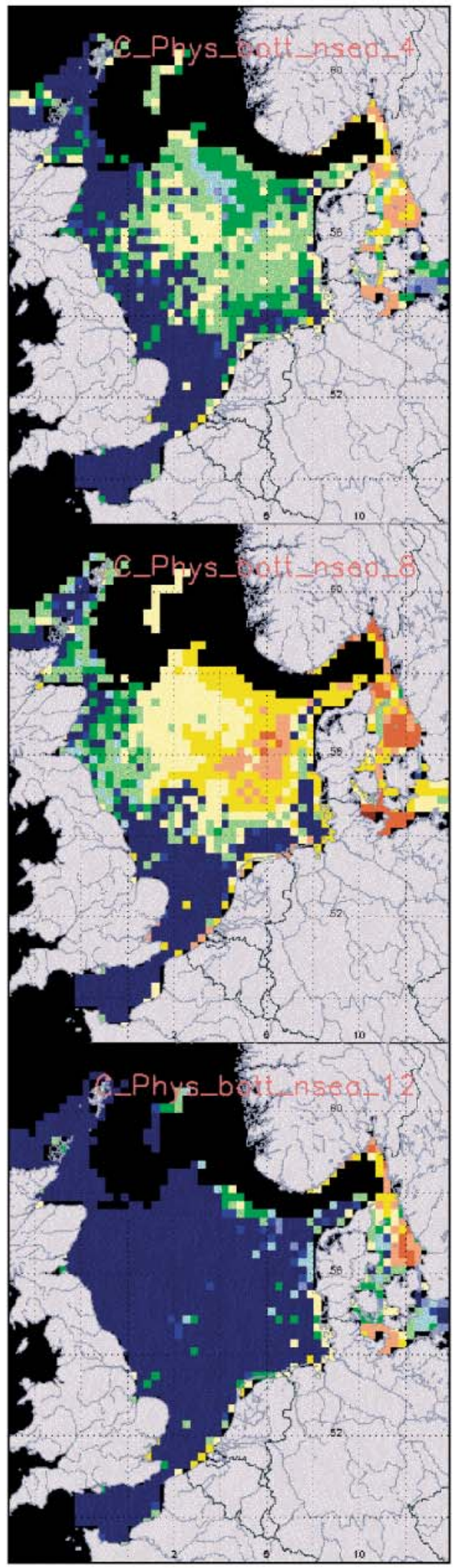

Fig. 5. Comparison of bottom physical index, C_phys_bott, for (a) the Adriatic Sea and (b) the North Sea in April, August and December (from top to bottom, respectively). Index represents low (high values $=$ red)/high (low values $=$ blue) physical availability of oxygen near sea bottom. Black area is not covered by model, or is water deeper than $100 \mathrm{~m}$ 
same nutrient availability as a function of upper-layer hydrology.

The bottom physical index, C_phys_bott, presented in Fig. 5 defines the oxygen availability in terms of both reserves and renewal. This index reveals the capacity of a coastal system to absorb a load of organic matter reaching the sea bottom. In other words, these maps show where oxygen deficiencies would occur near the bottom (high values of C_phys_bott = red) if the POM flux at the water-sediment interface was uniformly distributed. As for the surface physical processes, a seasonal variability in C_phys_bott is observed, but the main source of variation comes from the regional scale. Stratified shallow waters with low bottom friction appear to be particularly sensitive to organic loads reaching the seabed. These regions are the central North Sea, the SE shallow Skagerrak, the SW and SE Kattegat, the Kiel and Mecklenburg Bays, the northern Adriatic Sea and the Italian coast.

The effects of the surface and bottom physical characteristics on vulnerability to eutrophication are revealed by the PSA index (Fig. 6), which shows the location of oxygen deficiencies assuming that both nutrient and POM fluxes at the sea bottom are uniformly distributed. Hence, the PSA index provides, indirectly, a qualitative map of nutrient load thresholds that can be absorbed by the ecosystem without disturbance. Highest physical sensitivity generally occurs in summer, but enclosed areas can show a quasipermanent sensitivity, e.g. the Kiel and Mecklenburg Bays in Germany, the Gulf of Trieste, the eastern part of the Gulf of Venice, and the vicinity of the Po river mouth in Italy. In contrast, areas highly resistant to nutrient enrichment are located in tidally dominated areas, i.e. the SE North Sea and the English Channel. The PSA index illustrates the different degrees to which European shallow waters are able to combat eutrophication, as a function of their hydromorphology. This index clearly shows the relative physical capacity of coastal ecosystems to produce and incorporate organic matter in the surface and bottom layers, respectively. Similar and low nutrient loading in the Bay of Seine (France) and the Wash embayment (England) would be 'absorbed' by the coastal ecosystem without disturbance, but might lead to quasi-permanent anoxia in Kiel Bay (Germany) or in the NE Adriatic Sea. The buffering capacity of coastal shallow systems in 'digesting' organic matter is highly variable and directly linked with the physical environment; i.e. each ecological-hydromorphological system has its own maximum tolerance as regards nutrient levels above which food-web disturbances appear.

The above assesses the supporting factors of eutrophication (PSA), the assessment of the eutrophication risk (EUTRISK) itself is presented below. The
EUTRISK index uses phytoplankton production as the main vector of oxygen consumption near the bottom. In order to determine where the organic matter produced at the surface sinks to the seabed, vertical and horizontal POM transport is calculated using the advection produced by the model. Fig. 7 presents the results of POM export in the northern Adriatic Sea. The monthly mean satellite measurement of chlorophyll a in August 2000 (SeaWiFS-OC5, Fig. 7a) shows maximum biomass in front of and south of the Po delta. After transport is completed, i.e. when the POM has reached the seabed (Fig. 7b), the bottom POM load is concentrated exclusively south of the Po river mouth and further south along the Emilia-Romagna coast. Fig. 7c shows the integrated final distribution of bottom organic matter on the model grid. A comparison of the POM load for August 2000 in the North and Adriatic Seas (C_POM, Fig. 8) shows the limited extension of the highly productive areas: the EmiliaRomagna coast in the Adriatic Sea, the Bay of Seine, the Wash embayment, the southern North Sea coast, the German Bight and, to a lesser degree, Danish coastal waters and German coastal waters in the western Baltic Sea.

Assessment of the lowest oxygen concentration for a given month (EUTRISK) comprises calculation of oxygen consumption at the sea bottom (C_POM) and oxygen availability (C_phys_bott). Fig. 9 presents the EUTRISK index for August 2000. Comparison of the C_POM (Fig. 8), C_phys_bott (Fig. 5) and EUTRISK (Fig. 9) indices identifies 3 main types of eutrophicated waters: (1) eutrophic and sensitive, (2) mesotrophic and sensitive and (3) eutrophic and resistant. In the first category, oxygen depletion occurs regularly (red for EUTRISK, Fig. 9) because both the main pressure (red for C_POM, Fig. 8) and supporting factors (red for C_phys_bott, Fig. 5) are unfavourable; this category is represented by the Emilia-Romagna coastal waters south of the Po river mouth. In the second category, severe hypoxia or anoxia occur due to particularly adverse physical conditions, even when primary production is relatively low (red for C_phys_bott, Fig. 5; yellow to light blue for C_POM, Fig. 8; and yellow to red for EUTRISK, Fig. 9). In the SE Kattegat, primary production is low compared to eutrophic systems influenced by rivers and, even if satellite-derived production is underestimated through neglecting the subsurface chlorophyll a peak (see 'Discussion'), the results for the surface chlorophyll a distribution (data not shown) and POM flux to the bottom (Fig. 8) are consistent. In this area, despite mesotrophic conditions, permanent stratification leads to seasonal severe hypoxia (Baden et al. 1990a, EEA 2001), inducing a reduction in the benthic fauna (Baden et al. 1990a,b, Rosenberg et al. 1992). The 
a
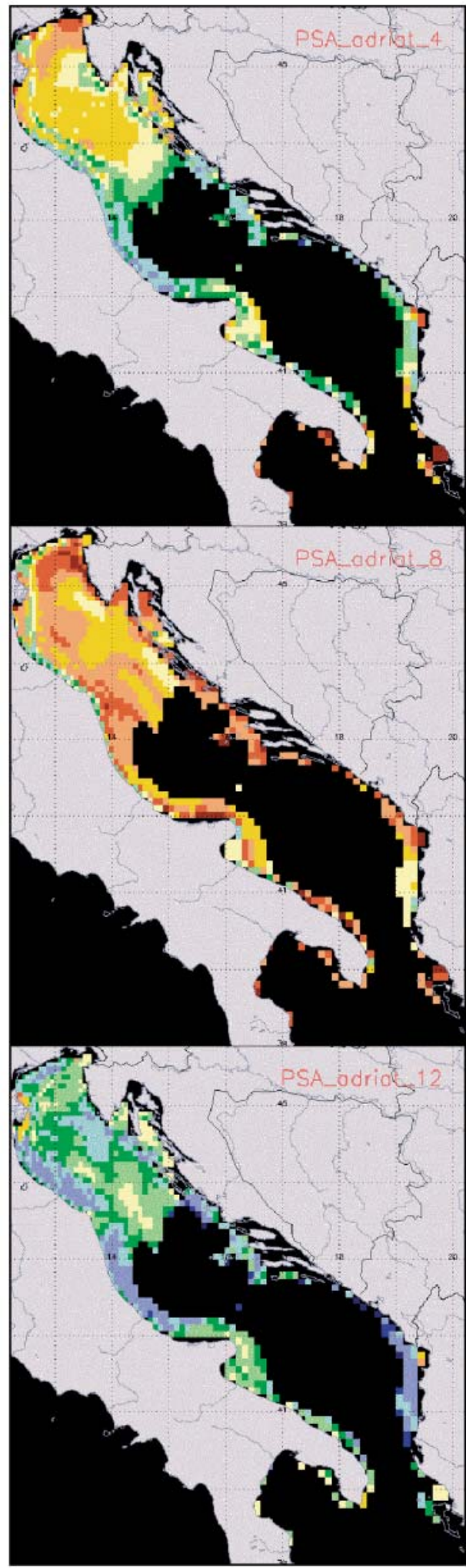

b

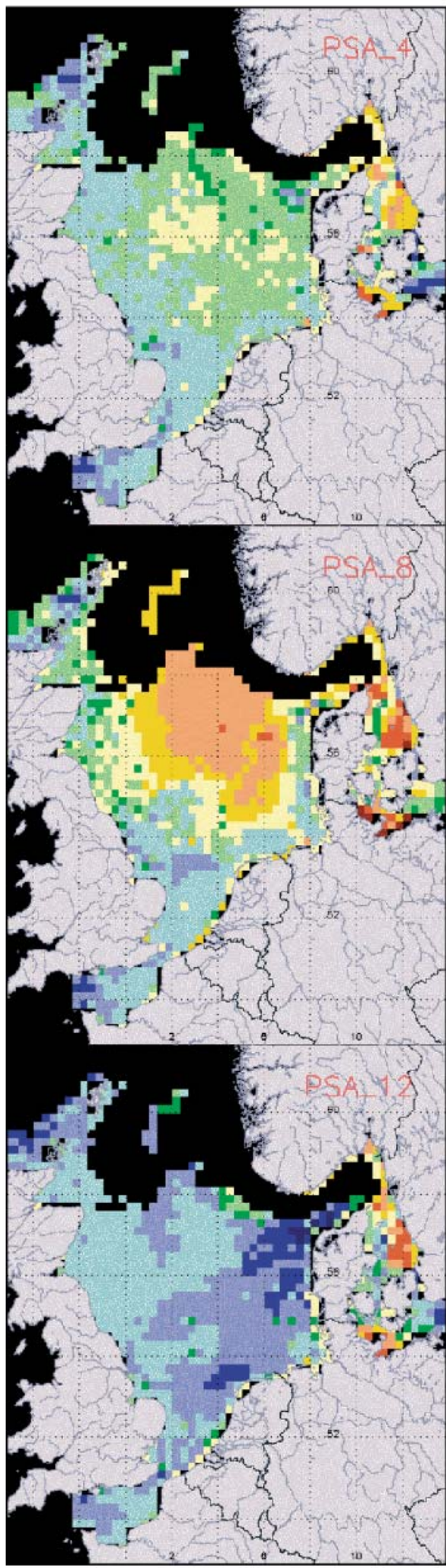

Fig. 6. Comparison of index of areas physically sensitive to eutrophication (PSA) based on 3-D hydrodynamic modelling results for (a) the Adriatic Sea and (b) the North Sea in April, August and December (from top to bottom, respectively). Index represents high $($ high values $=$ red)/low (low values $=$ blue) physical sensitivity to eutrophication due to diverse physical conditions. Black area is not covered by model, or is water deeper than $100 \mathrm{~m}$ 
a

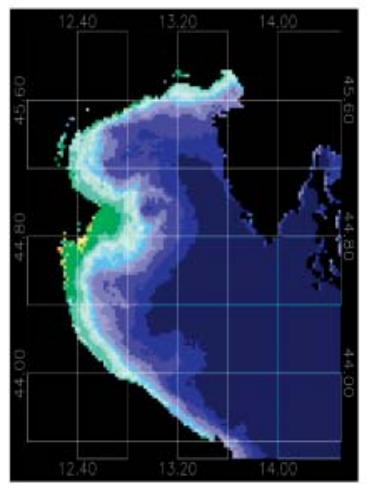

b

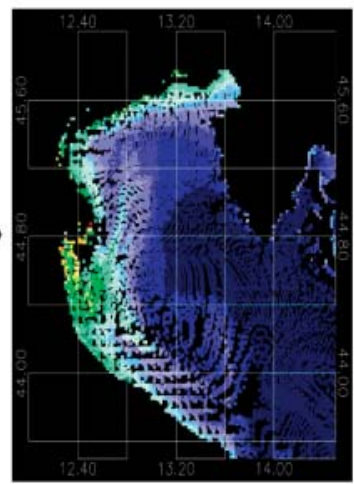

C

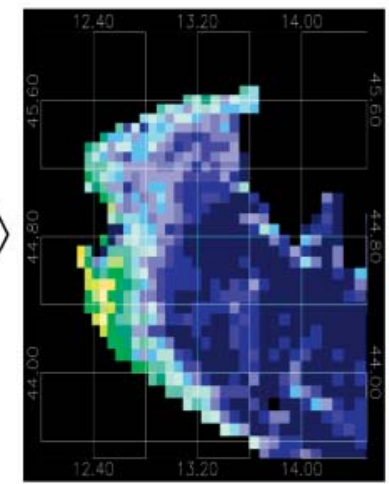

Fig. 7. Transport procedure particularly required for the northern Adriatic Sea where organic matter production (POM area), and sinking area are different. (a) Monthly mean primary production estimated for August 2000 (in relative units); (b) final distribution of POM after horizontal and vertical advection procedure using the model velocity field; and (c) summary on model grid to derive the load of organic matter at sea bottom

third category concerns areas where near-bottom waters are protected from severe hypoxia by permanent, strong, vertical mixing; however, food-web alteration and the development of opportunistic species are generally observed, e.g. in the Bay of Seine and in Wash embayment (blue for C_phys_bott, Fig. 5; red for C_POM, Fig. 8; and yellow for EUTRISK, Fig. 9). On the EUTRISK scale, blue and green correspond to non-problem areas, although green colour does indicate higher potential vulnerability. Yellow and red correspond to 2 levels of eutrophication where food-web alterations and/or hypoxia characterise an intermediate step, and severe hypoxia or anoxia the ultimate level.

\section{DISCUSSION}

\section{Validation}

The EUTRISK index is validated using dissolved oxygen concentration at the sea bottom. Linked to the EUTRISK index (see Fig. 9), an oxygen scale $\left(\mathrm{mg} \mathrm{l}^{-1}\right.$ ) represents the risk of oxygen deficiency, i.e. the lowest near-bottom oxygen content for the considered month. The high temporal and spatial variability in oxygen content in shallow waters makes validation difficult, especially on a pan-European scale. An ideal set of measurements is provided by buoys with a quasicontinuous monitoring (hourly sampling) at a fixed a

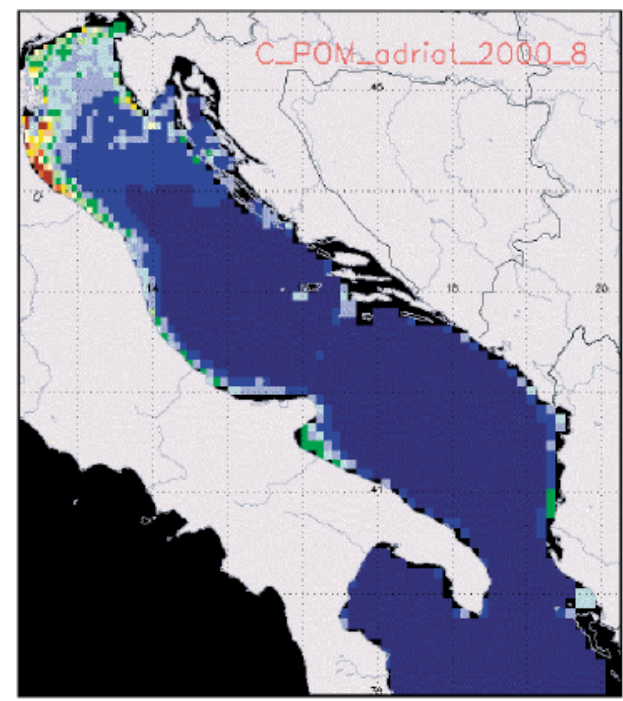

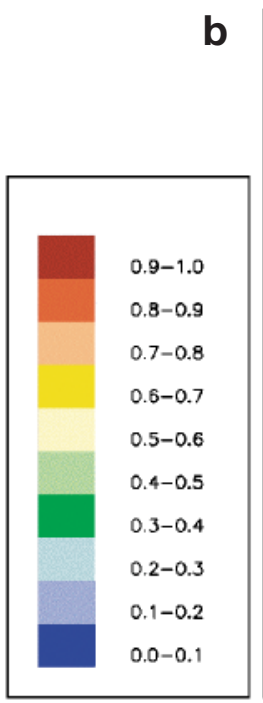

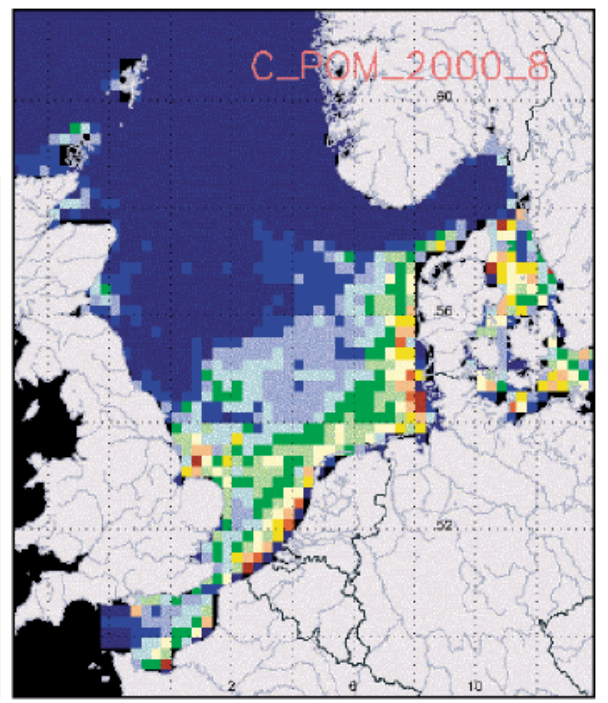

Fig. 8. Comparison of particulate organic matter index, C_POM, in (a) the Adriatic Sea and (b) the North Sea in August 2000. C_POM index represents monthly relative organic load of matter that reaches the seabed (or $100 \mathrm{~m}$ for deep waters) estimated primarily from satellite-derived chlorophyll $a$ which has undergone horizontal and vertical transport and degradation in the water column. Black area is not covered by model 

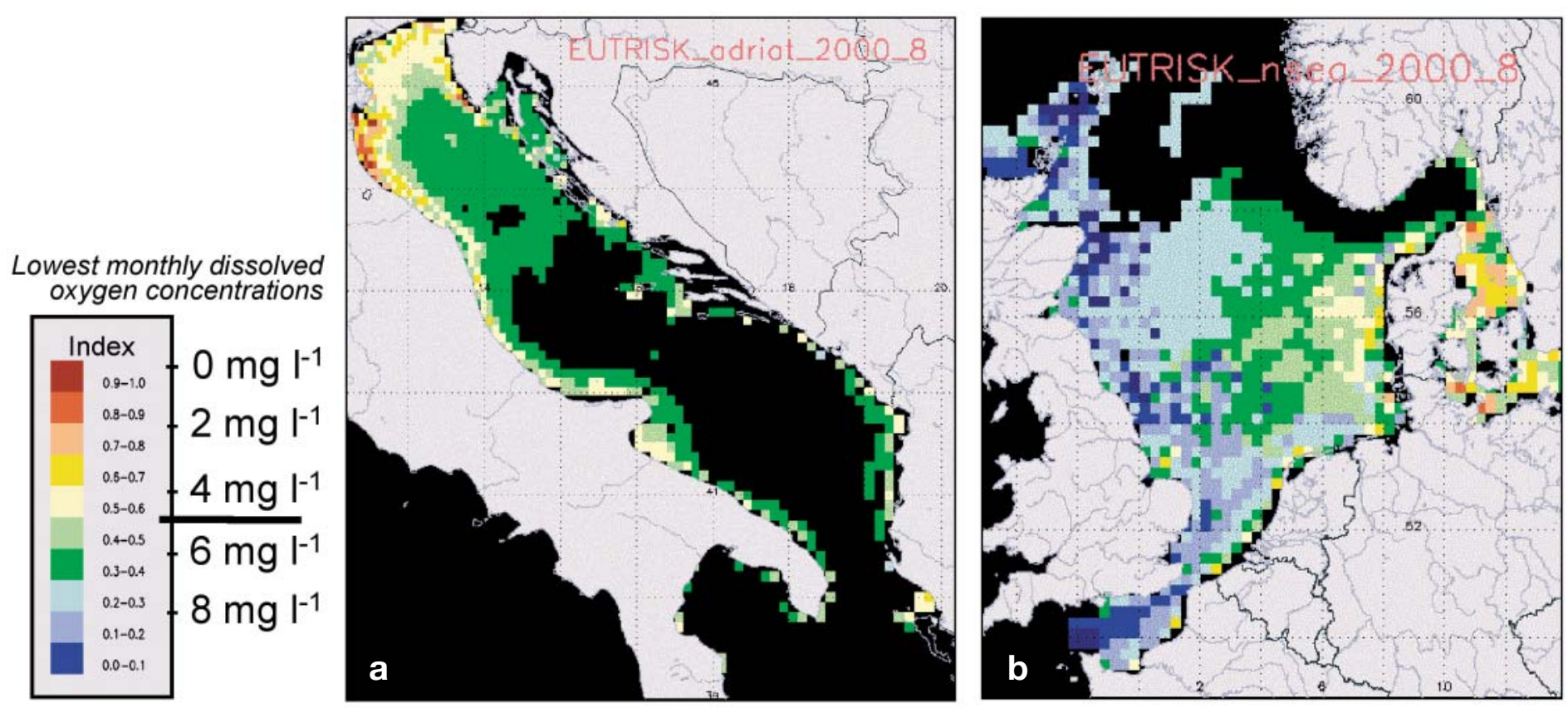

Fig. 9. Comparison of eutrophication risk index, EUTRISK, based on 3-D hydrodynamic modelling results and remote-sensing of ocean colour in (a) the Adriatic Sea and (b) the North Sea in August 2000. EUTRISK index represents most probable oxygen deficiency distribution near sea bottom for month considered. Black area is not covered by model, or is water deeper than $100 \mathrm{~m}$

location. The buoys should be located in a fairly homogeneous area for comparison with model results or satellite observations. As already mentioned in 'Results', due to tide-induced vertical mixing, the buoys in the Bay of Seine did not measure bottom oxygen contents below $5.0 \mathrm{mg} \mathrm{l}^{-1}$ despite the high phytoplankton biomass recurrently sampled. Comparatively, the corresponding EUTRISK index for August 2000 (Fig. 9b) and August 1998 (result not shown) estimates a minimum bottom oxygen value between 4 and $5 \mathrm{mg} \mathrm{l}^{-1}$ (light yellow) and between 3 and $4 \mathrm{mg} \mathrm{l}^{-1}$ (dark yellow) for August 1999 (result not shown).

The high variability in oxygen content near the seabed in the Adriatic Sea is illustrated in Fig. 10. Weekly measurements in the summer months along the EmiliaRomagna coast recorded the occurrence of oxygen depletion or severe deficiency over the period of a few days. Fig. 10 shows the sequential succession and the 2 main locations of oxygen depletion (white lines). On 4 and 13-14 August 1998, depletion was located in the southern part of the area between Ravenna and Cesenatico (corresponding to the 2 southern transects); however, between these 2 dates, on 8 August, the depletion was located along the coast south of the Po delta (between the 2 northern transects). This variability can be explained by a change in wind conditions and the resultant vertical mixing. Before 5 August, a light variable wind (Fig. 11) induced low vertical mixing, and the regions corresponding to the maximum
POM load (southern area in Fig. 8a) were the most impacted. Between 5 and 8 August, a moderate wind event from the northeast increased vertical mixing in the southern part. In contrast, the protection offered by the Po delta limited the fetch, and wave-induced mixing led to oxygen depletion in the northern part. This area corresponds to the second maximum in POM deposition (Fig. 8a). The anoxia in the southern part on 13-14 August and the hypoxia in the northern part on 18 August were partly the result of low wind conditions over a few days. After 21 August, with a higher and rotating wind, anoxia tended to evolve to hypoxia. The overlay of the EUTRISK index on the oxygen depletion measured in August 1998 (Fig. 10) shows good agreement with respect to the sampling network (pink dots and lines in Fig. 10). This example reveals how cautiously EUTRISK validation must be done.

Another investigation to test the applicability of the approach is to simulate the EUTRISK index, halving the primary production to the level reported in many European coastal seas between the 1950s and 1970s. A reasonable assumption for the test is that meteorological forcing and hydrology were stable over the last $50 \mathrm{yr}$, apart from the Kattegat and Belt Sea area where the inflow of bottom water is critical for oxygen conditions (HELCOM 2003) and highly variable. A doubling of the primary production between the 1950s or 1970s and the 1990s was reported for the southern Kattegat (Richardson \& Heilmann 1995), the Belt Sea (Halskov 


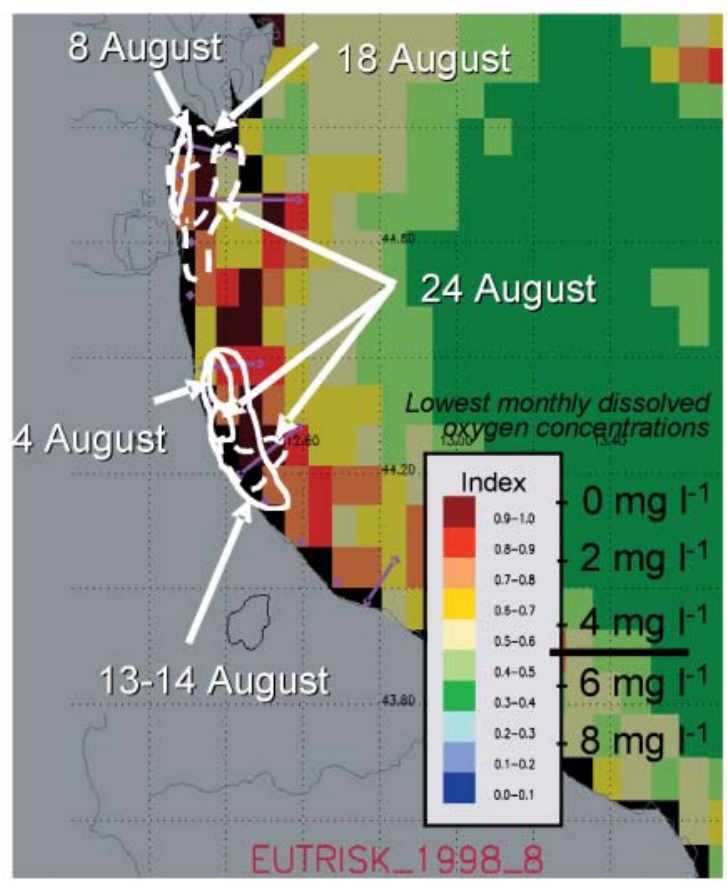

Fig. 10. Comparison of eutrophication risk index, EUTRISK, and in situ measurements of bottom dissolved oxygen in August 1998 in Emilia-Romagna coast area (south of Po delta); measured anoxia $\left(<2 \mathrm{mg} \mathrm{l}^{-1}\right)$ is represented in by continuous white lines, hypoxia $\left(<4 \mathrm{mg} \mathrm{l}^{-1}\right)$ by dashed white lines. Monitoring stations (pink squares and lines) were sampled each week by ARPA (Agenzia Regionale Prevenzione e Ambiante dell'Emilia-Romagna). Note temporal and spatial variability in oxygen deficiencies

Rev: Rydberg et al. 1990), and the Dutch Wadden Sea (de Jonge 1990). A doubling of algae biomass occurred during the same period along the Dutch coast (Cadée 1992, Riegman 1995). The increased production of organic matter was associated with a decrease in dissolved oxygen concentrations in bottom waters over the same period in the southern Kattegat (Christensen 1988), Kiel Bay (Babenerd 1991), the German Bight (Hickel et al. 1989) and the northern Adriatic Sea (Justić 1987, Degobbis et al. 2000). The same evolution was retrieved from the foraminiferal record for the northern Adriatic Sea (Barmawidjaja et al. 1995). If primary production is halved, almost all severe hypoxic areas indicated by the EUTRISK index for August 2000 (Fig. 9) are shown as non problem areas $\left(>4 \mathrm{mg} \mathrm{l}^{-1}\right.$, Fig. 12), in agreement with the historical evolution of eutrophication. Anoxia was reported as early as in the 1950s along the Emilia-Romagna coast in the Adriatic Sea (D. Fontana, Regione della Romagna, pers. comm.). The maximum assimilating capacity of organic matter has been reached and largely surpassed in many European marine waters during the last 50 yr. Physically resistant water bodies with high productivity are pro-
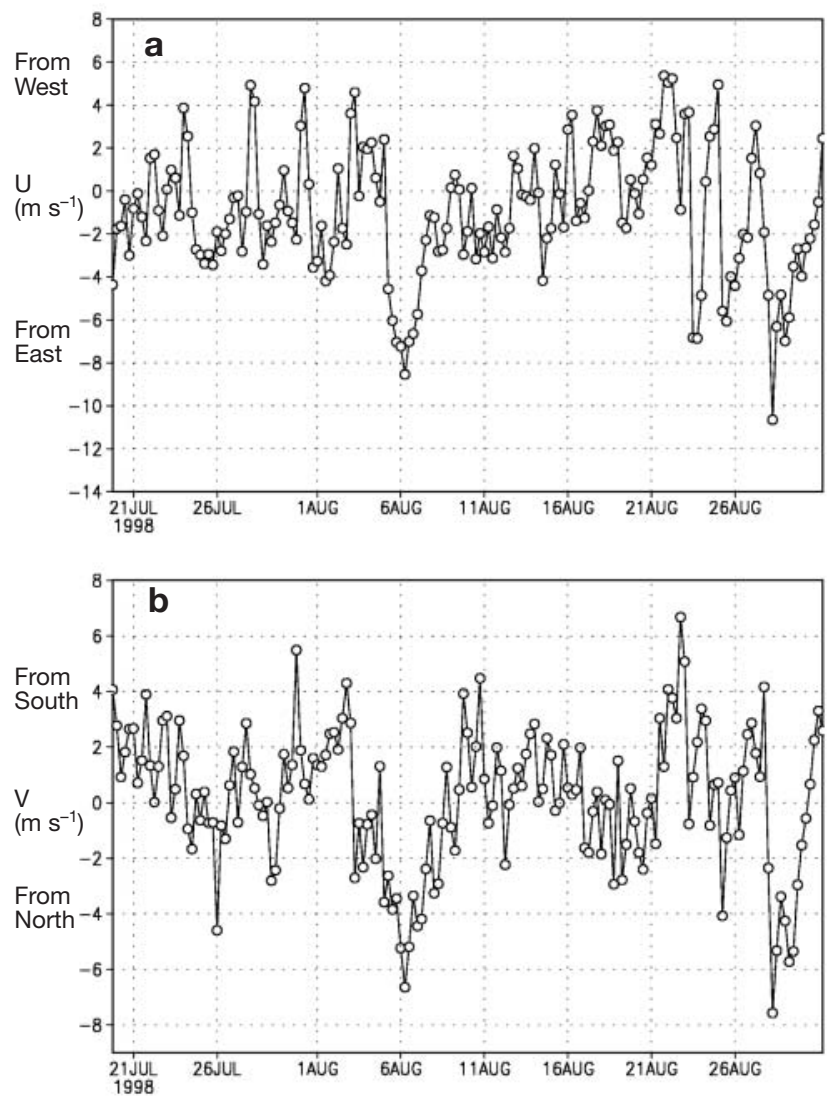

Fig. 11. Wind components at $10 \mathrm{~m}$ from the European Centre for Meteorological and Weather Forecast (ECMWF) reanalysis of point located south of the Po river delta $\left(44.6^{\circ} \mathrm{N}\right.$, $12.5^{\circ} \mathrm{E}$ ). (a) $\mathrm{U}$, longitudinal; (b) $\mathrm{V}$, latitudinal. Note wind change on 6 August in relation to variability in oxygen deficiencies in Fig. 10

tected from sea-bottom hypoxia by tidal-induced vertical mixing. However, like other eutrophicated water masses, these highly mixed waters are generally subject to communities changes which alter the food-web structure and functioning. Unusual phytoplankton blooms are responsible for various eutrophication phenomena, such as the mucilage of Phaeocystis spp. in the southern North Sea (Lancelot 1995, Riegman 1995) or toxicity to humans in the form of diarrhoeic shellfish poisoning (DSP) in the Bay of Seine (Dinophysis spp.: Lassus et al. 1988, Belin et al. 1989), or invertebrate mortality associated with Gyrodinium cf. aureolum (=Gymnodinium cf. nagasakiense) in the Bay of Somme (Belin et al. 1989). This form of eutrophication is emphasised (see yellow colour on the EUTRISK scale in Fig. 9b) in coastal waters of west Denmark, the German Bight, the Netherlands (off the Wadden Sea, Marsdiep and in the Rhine/Meuse plume area), Belgium, France (near the Bay of Somme and Bay of Seine) and UK (off of the Humber and Southampton estuaries and the Wash embayment). Such systems are 
Lowest monthly dissolved oxygen concentrations
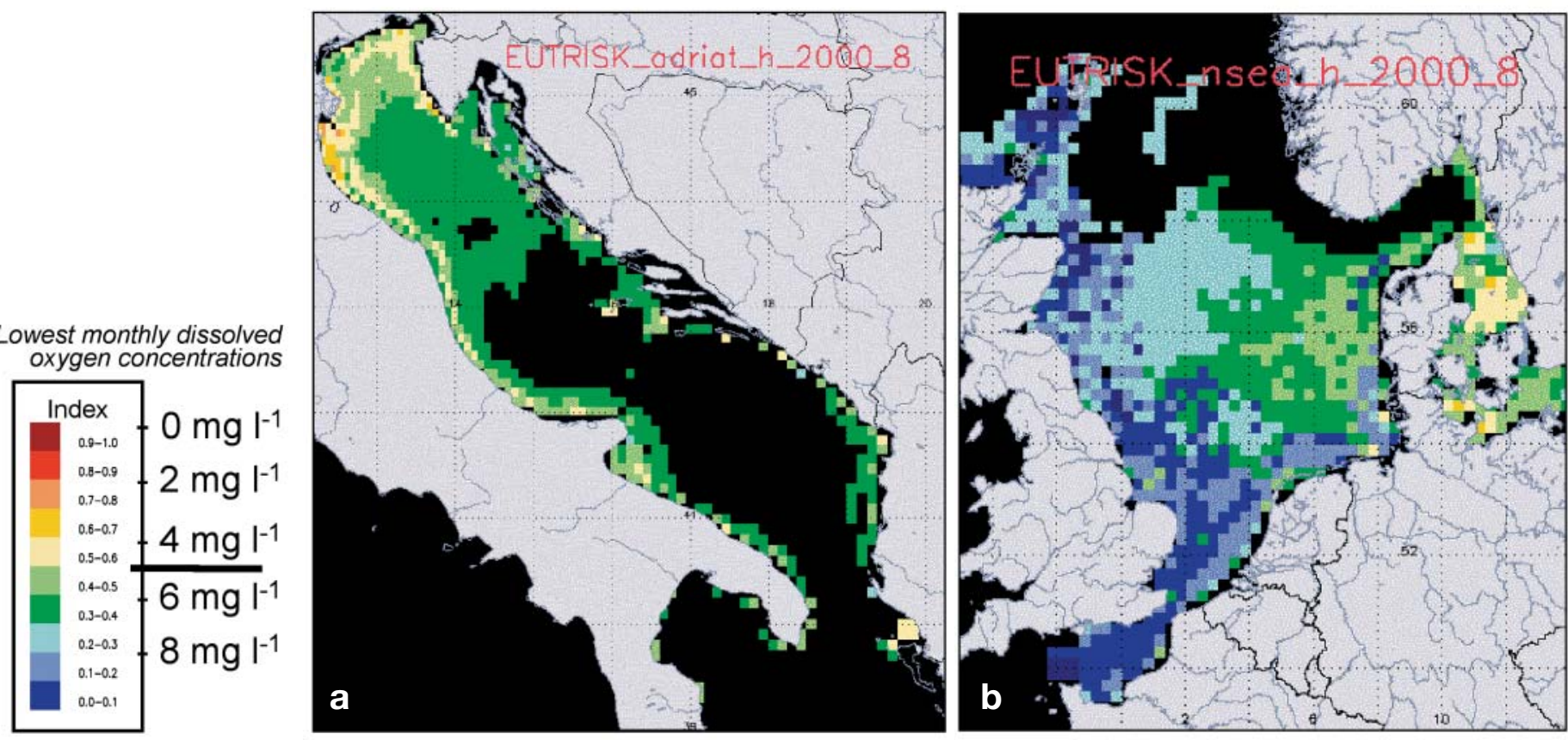

Fig. 12. Eutrophication risk index, EUTRISK, with 50 \% biomass reduction scenario (corresponding to the biomass in the period 1950 s-1970s compared to recent years [2000 here]) in (a) the Adriatic Sea and (b) the North Sea. EUTRISK index represents most probable oxygen deficiency distribution near the sea bottom. Black area is not covered by model, or is water deeper than $100 \mathrm{~m}$

all relatively resistant (generally dark green/blue in August for C_phys_bott, Fig. 5b) but under pressure from high nutrient loads and resulting organic matter production (red colour for C_POM, Fig. 8b).

Another category of eutrophication is shown by EUTRISK in the NE part of the northern Adriatic Sea (north of $45.25^{\circ} \mathrm{N}$ and east of $12.50^{\circ} \mathrm{E}$, see Fig. 9a). This type of system, which has the same EUTRISK classification (yellow colour) as the previous category, is slightly mesotrophic or even oligotrophic (Fig. 8a), but highly sensitive (Fig. 5a). Anoxic events $(<2 \mathrm{mg}$ $\mathrm{l}^{-1}$ ) have been reported by Šimunović et al. (1999), whereby fish kills were linked to the particularly low circulation in the centre of current eddies. For the Bay of Trieste, Šimunović et al. (1999) refer to the work of Malej (1993), who stated that the occurrence of hypoxia and anoxia did not appear to be related to eutrophication but rather to the combined impact of morphological and hydrographic factors. The physical characteristics given by the hydrodynamical model based on climatology support this hypothesis. Both circulation and bottom friction are very low, the water column is stratified in summer, oxygen saturation is minimum, and the thickness of the benthic layer is critical. Consequently, the high values of the C_phys_bott and PSA indices reveal an elevated physical sensitivity of the extreme northern Adriatic and particularly its low oxygen reserve and renewal capacity in the deeper layer.

\section{Limitations to indices}

The first limitation of PSA and EUTRISK is geographical, resulting from the modelling and remote-sensing capabilities used. No data are available for the coastline using both tools. With a spatial resolution of 4 to $20 \mathrm{~km}$, the physical models cannot provide accurate information for the first few kilometres off the sea shore, nor can the optical remote-sensing measurement because the first few sea pixels might contain land information.

Another more spatially restricted limitation occurs for very shallow waters where the penetration depth of light $\left(Z_{90}\right)$ is deeper than the water depth and the remote sensor detects the sea bottom. The penetration depth defined for an homogeneous ocean is $Z_{90} \approx k^{-1}$ (Gordon \& McCluney 1975); if the attenuation coefficient for downwelling irradiance $(k)$ is low (i.e. if the water is clear), $Z_{90}$ is high and may exceed the water depth. This phenomenon may arise locally in the western Kattegat, where large areas are between 5 and $15 \mathrm{~m}$ deep. However this concerns only very low chlorophyll contents, as $Z_{90}$ drops from $13 \mathrm{~m}$ for $0.20 \mathrm{mg}$ chlorophyll $\mathrm{a} \mathrm{m}^{-3}$ to $2.5 \mathrm{~m}$ for $2.0 \mathrm{mg}$ chlorophyll a $\mathrm{m}^{-3}$ (data not shown), and the penetration depth is even less for turbid waters.

The model resolution limits the sub-grid-point accuracy, especially for the actual North Sea results $(20 \mathrm{~km}$ cell size) where hydrodynamics below this scale cannot be correctly represented. For small-scale morpho- 
logical systems like the Belt Sea, where the hydrodynamics are defined by the complex archipelago, the relatively gross hydromorphology might generate approximation in the results.

The interannual variability of the physical environment is a significant factor influencing eutrophication that is not currently contained in the hydrodynamical model results (which are monthly means based on climatology or several years' means). The SE North Sea experienced large events of anoxia and hypoxia in 1981, 1982 and 1983 and, to a lower degree, in 1989 and 1994, that were reported to be related to warm calm-weather periods during summer (Dethlefsen \& von Westernhagen 1983, Brockmann \& Eberlein 1986, Hickel et al. 1989, Gerlach 1990, Niermann 1990). No severe hypoxia was observed in the northern German Bight and Jutland coastal waters in August for the years 1998, 1999, 2000 and 2001 (see the National Environmental Research Institute of Denmark [NERI] Cruise Reports [available at: www.dmn.dk/1_om_dmu/ 2_afdelinger/3_hav/CruiseReports/index.htm]). In particular, no hypoxia was measured in that area for the period August-October 2000 (EEA 2001) in agreement with the EUTRISK estimate for August 2000 as well as for August 1998 and 1999 (results not shown). As further developments, the use of satellite-derived seasurface temperature will allow us to include the major multi-annual variability in the physical environment and to increase the accuracy of the indices for a considered year.

The monthly average for the physical parameters acts as a filter of short-term variability and highlights the temporally most dominant processes. As a next step, the relative importance of weekly or daily variability of physics could be examined. Regarding biological processes, the monthly resolution of the indices constitutes a limitation, when one considers the rapid fluctuations in carbon and oxygen contents in the strong pelagic-benthic coupling of shallow ecosystems. In the previous discussion we explained why a risk evaluation is proposed rather than a direct assessment. A weekly timescale would most probably significantly improve the results; however, technical problems would have to be resolved such as reduced remote-sensing coverage and temporal integration of organic matter. Increasing the temporal resolution would be fully beneficial only if proper modelling of the chemical elements involved (carbon and oxygen) were performed rather than an index approach.

In addition to temporal resolution, the main approximation involves estimation of primary production by surface chlorophyll a concentrations. Primary production estimates depend on the chlorophyll a-normalised rate of carbon fixation, the photosynthetically available radiation (PAR), the euphotic depth, the vertical distrib- ution of chlorophyll a and photoperiod (Behrenfeld \& Falkowski 1997). The correlation between primary production and surface chlorophyll a content alters as a function of changes in the algal community composition and in the PAR during the growing season. Nevertheless, at monthly time scales, PAR and the dominant phytoplankton group (mainly diatoms and dinoflagellates) are considered stable. Hence, in areas where subsurface production is low, variability in primary production is assumed to depend mainly on surface chlorophyll a content. The EUTRISK index was calibrated for the months August and September, and consequently is not valid for spring months in its present version.

The subsurface peak of chlorophyll a observed after the spring bloom in stratified areas is generally too deep to be detected by optical remote-sensing. Therefore, primary production is estimated on the basis of surface production only. Consequently, neglecting the subsurface production in upper, clear waters might lead to a significant underestimation of primary production. In one of the areas most physically sensitive to oxygen depletion, the southern Kattegat, Richardson \& Christoffersen (1991) and Carstensen et al. (2003) estimated the contribution of subsurface production to be in the order of 30 to $35 \%$ of annual production. Assuming that subsurface production dominates during $6 \mathrm{mo}$, it can contribute up to 60 or $70 \%$ of the summer production. Such underestimation in the southern Kattegat together with the unfavourable near-bottom physical conditions (C_phys_bott, Fig. 5) leads to a significant underestimation of oxygen deficiency. In fact, large areas of the southern Kattegat and Belt Sea have been recurrently affected by hypoxia and anoxia over the last decade (mainly due to permanent stratification and low bottom-water exchange: HELCOM 2003), whereby EUTRISK revealed only hypoxia. Comparatively, the central North Sea is characterised by a higher physical resistance (Fig. 5) and by a lower contribution of the subsurface production (ca. $36 \%$ of the summer production: Richardson et al. 1998), as its chlorophyll maximum is deeper. When doubling the primary production in the presented simulation, the EUTRISK index accordingly predicts anoxia for the southern Kattegat (red, results not shown) and no problem area (blue and green, results not shown) for the central North Sea.

Despite an underestimation due to the subsurface peak, the primary production estimated by remotesensing reflects the general levels of low, medium and high productivity in the investigated areas. Primary production in August and September in the SE Kattegat is generally lower than in eutrophic systems influenced by rivers. Mean values range from ca. $350 \mathrm{mg} \mathrm{C} \mathrm{m}^{-2} \mathrm{~d}^{-1}$ in the centre of the area (Stn 413, upper 10 m, 1989 to 1997, Carstensen et al. 2003, their 
Fig. 5E) to ca. $880 \mathrm{mg} \mathrm{C} \mathrm{m}^{-2} \mathrm{~d}^{-1}$ (water column, 1981 to 1985, Rydberg et al. 1990) in Laholm Bay (on the Swedish coast, $56.55^{\circ} \mathrm{N}, 12.80^{\circ} \mathrm{E}$ ), which has a large freshwater input. In comparison, the regional summer mean of primary production in the offshore part of the German Bight was estimated to be ca. $925 \mathrm{mgC}$ $\mathrm{m}^{-2} \mathrm{~d}^{-1}$ and for the central North Sea ca. $325 \mathrm{mg} \mathrm{C}$ $\mathrm{m}^{-2} \mathrm{~d}^{-1}$ (mean values for August and September, 1988 and 1989: Joint \& Pomroy 1993, their Fig. 12) to $414 \mathrm{mg} \mathrm{C} \mathrm{m}^{-2} \mathrm{~d}^{-1}$ (August 1991: Richardson et al. 1998). The annual primary production reported for the Kattegat (water column, 1989 to 1997: Carstensen et al. 2003) is ca. $157 \mathrm{~g} \mathrm{C} \mathrm{m}^{-2} \mathrm{yr}^{-1}$, with $144 \mathrm{~g} \mathrm{C} \mathrm{m}^{-2} \mathrm{yr}^{-1}$ for the SE Kattegat (1981 to 1988: Rydberg et al. 1990). Joint \& Pomroy (1993) found, as mean regional values, $261 \mathrm{~g} \mathrm{C} \mathrm{m}^{-2} \mathrm{yr}^{-1}$ for the German Bight and $119 \mathrm{~g} \mathrm{C}$ $\mathrm{m}^{-2} \mathrm{yr}^{-1}$ for the central North Sea. The Kattegat has therefore an intermediate primary production between the central North Sea and the German Bight, in agreement with the satellite-derived chlorophyll a distribution (data not shown) and the POM flux to the bottom (Fig. 8b). Note that marine waters influenced by rivers, which are the most common hot-spots of humaninduced eutrophication, are not affected by this inaccuracy as the high primary-production level occurs near the surface. It is therefore concluded that the use of satellite-derived primary production is generally relevant for estimating the eutrophication risk in coastal waters as the first-order variability in space and time is reflected. In the case of the southern Kattegat and Belt Seas, the relatively shallow subsurface production can dominate the summer water-column production; however, due to their specific hydromorphological conditions, whereby sills and a permanent stratification isolate the bottom-water masses, the bottom-water exchange was shown to largely control the oxygen deficiency (HELCOM 2003). Remote-sensing data represent a satisfactory compromise between accuracy and temporal and spatial coverage of the investigated areas.

\section{CONCLUSION}

The EUTRISK and PSA indices assess the ecosystem status and physical sensitivity to eutrophication, respectively. We compared 2 shallow seas characterised by different hydromorphological conditions: the Adriatic Sea and the North Sea. The 3 main types of eutrophicated shallow ecosystems originally identified could be separated into a slightly more refined classification: eutrophic or hypertrophic and sensitive (recurrent anoxia, e.g. south of the Po river delta); mesotrophic and hyper-sensitive (recurrent anoxia, e.g. Kattegat and Belt Sea); oligo- or lower-mesotrophic and hyper-sensitive (aperiodic anoxia or hypoxia, e.g. NE part of the northern Adriatic Sea); higher-mesotrophic or eutrophic and resistant (only exceptional hypoxia, e.g. German Bight); and finally eutrophic or hypertrophic and hyper-resistant (no hypoxia, e.g. Bay of Seine). The eutrophicated ecosystems in which hypoxia is prevented by favourable hydromorphological conditions are however affected by food-web alterations and functioning, leading to the development of opportunistic algae.

The PSA and EUTRISK indices constitute the basis for an environmental tool for policy managers from a regional to a European level. These first, promising, results were aimed at testing the robustness of the approach. Hot-spots in terms of physical vulnerability and hypoxia risk have been emphasised. An extension of the indices to all European shallow marine systems will allow comparison of eutrophication types and intensity as well as evolution over time, and should attempt to fill in the gap, for areas where research effort on eutrophication has been relatively poor (e.g. Black and Mediterranean Seas: Vidal et al. 1999). The indices identify areas in which to invest effort for restoration and the relative cost for restoring to their pristine ecological status. This approach to marine eutrophication provides an answer to a fragment of the Phase III conceptual model in the review of Cloern (2001), which includes multiple stressors, a filter that modulates ecosystem responses, the multiple responses themselves, impacts on the Earth's system including aspects that influence sustainability of the human population, and scientifically sound tools for building rational management strategies. PSA and EUTRISK focus on the main stressor of eutrophication, i.e. nutrient enrichment; they include the physical environment as a filter, and provide a large spatial and temporal view of the main ecosystem responses, i.e. the production of organic matter and the oxygen budget. A preliminary comparative assessment of the mechanisms involved, and in particular the level of nutrient reduction using the PSA index (assuming discharges are known), allows the estimation of the relative cost for restoration, which is a prerequisite for developing efficient management strategies on a large scale.

Acknowledgements. The authors would like to thank the SeaWiFS Project (Code 970.2) and the Distributed Active Archive Center (Code 902) at the Goddard Space Flight Center, Greenbelt, MD 20771, for the production and distribution of the SeaWiFS data, respectively. These activities are sponsored by NASA's 'Mission to Planet Earth Program'. The authors thank F. Mélin for processing the SeaWiFS data. Further we would especially like to acknowledge T. Pohlmann, who provided us with the daily model data, and K. Bolding, who converted the CRAY binary data into netcdf format. We are grateful to A. S. Heiskanen and N. Hoepffner for critical comments and suggestions. 


\section{LITERATURE CITED}

Abdullah MI, Danielsen M (1992) Chemical criteria for marine eutrophication with special reference to the Oslofjord, Norway. Hydrobiologia 235/236:711-722

Alldredge AL, Gotschalk CC (1989) Direct observations of mass flocculation of diatom blooms: characteristics, settling velocities and formation of diatom aggregates. Deep-Sea Res 36:159-171

Aminot A, Guillaud JF, Kérouel R (1997) La baie de Seine: hydrologie, nutriments et chlorophylle (1978-1984). Éditions IFREMER, Repères Océan 14, IFREMER, Plouzané

Archer JR, Mark MJ (1997) Control on nutrient losses to water from agriculture in Europe. Proc Int Fert Soc 405:1-32 (also available at: www.fertiliser-society.org/Proceedings/ Prc405.htm

Babenerd B (1991) Increasing oxygen deficiency in Kiel Bay (western Baltic). A paradigm of progressing coastal eutrophication. Meeresforschung 33:121-140

Baden SP, Loo LO, Pihl L, Rosenberg R (1990a) Effects of eutrophication on benthic communities including fish: Swedish west coast. Ambio 19:113-122

Baden SP, Pihl L, Rosenberg R (1990b) Effects of oxygen depletion on the ecology, blood physiology and fishery of the Norway lobster Nephrops novergicus. Mar Ecol Prog Ser 67:141-155

Barmawidjaja DM, van der Zwaan GJ, Jorissen FJ, Puskaric S (1995) 150 years of eutrophication in the northern Adriatic Sea: evidence from a benthic foraminiferal record. Mar Geol 122:367-384

Behrenfeld MJ, Falkowski PG (1997) Photosynthetic rates derived from satellite-based chlorophyll concentration. Limnol Oceanogr 42:1-20

Belin C, Berthome JP, Lassus P (1989) Dinoflagellés toxiques et phénomènes d'eaux colorées sur les côtes françaises: évolution et tendances entre 1975 et 1988. Hydroécol Appl 1/2:3-17

Brockmann U, Eberlein K (1986) River input of nutrients into the German Bight. NATO ASI Ser G Ecol Ser 7:231-240

Cadée GC (1992) Phytoplankton variability in the Marsdiep, the Netherlands. ICES Mar Sci Symp 195:213-222

Carstensen J, Conley D, Müller-Karulis B (2003) Spatial and temporal resolution of carbon fluxes in a shallow coastal ecosystem, the Kattegat. Mar Ecol Prog Ser 252:35-50

Christensen PB (1988) The Danish marine environment: has action improved its state? Marine research program HAV90. In: Christensen PB (ed) Havforskning fra Miljøstyrelsen 62. Danish Environmental Agency, Copenhagen

Cloern JE (1999) The relative importance of light and nutrient limitation of phytoplankton growth: a simple index of coastal ecosystem sensitivity to nutrient enrichment. Aquat Ecol 33:3-16

Cloern JE (2001) Our evolving conceptual model of the coastal eutrophication problem. Mar Ecol Prog Ser 210:223-253

Cognetti G (2001) Marine eutrophication: the need for a new indicator system. Mar Pollut Bull 42:163-164

Cugier P (1999) Modélisation du devenir à moyen terme dans l'eau et le sédiment des éléments majeurs ( $N, P, S i)$ rejetés par la Seine en Baie de Seine. PhD thesis, Université de Caen

Dale VH, Beyeler SC (2001) Challenges in the development and use of ecological indicators. Ecol Indicators 1:3-10

Danilov RA, Ekelund NGA (2001) Comparative studies on the usefulness of seven ecological indices for the marine coastal monitoring close to the shore on the Swedish coast. Environ Monit Assess 66:265-279

Degobbis D, Precali R, Ivancic I, Smodlaka N, Fuks D, Kveder
S (2000) Long-term changes in the northern Adriatic related to anthropogenic eutrophication. Int $\mathrm{J}$ Environ Pollut 13:495-533

de Jonge VN (1990) Response of the Dutch Wadden Sea ecosystem to phosphorus discharges from the River Rhine. Hydrobiologia 195:49-62

Demirov E, Eifler W, Ouberdous M, Hibma N (1998) ISPRAMIX - a three dimensional free surface model for coastal ocean simulations and satellite data assimilation on parallel computers. Part I. Description and validation of the model. Tech Rep EUR 18129, European Commission, Joint Research Centre, Ispra

Dethlefsen V, von Westernhagen H (1983) Oxygen deficiency and effects on bottom fauna in the eastern German Bight 1982. Meeresforschung 30:42-53

Diaz RJ (2001) Overview of hypoxia around the world. J Environ Qual 30:275-280

Diaz RJ, Rosenberg R (1995) Marine benthic hypoxia: a review of its ecological effects and the behavioural responses of benthic macrofauna. Oceanogr Mar Biol Annu Rev 33:245-303

Dobricic S (2002) Sensitivity of an ocean-atmosphere model of the Adriatic Sea on coupling scheme and resolution of the atmospheric model. PhD thesis, Institut für Meereskunde, Hamburg

Druon JN, Le Fèvre J (1999) Sensitivity of a pelagic ecosystem model to variations of process parameter within a realistic range. J Mar Syst 19:1-26

EEA (European Environmental Agency) (2001) Eutrophication in Europe's coastal waters. Topic Report 7/2001. EEA, Luxembourg (also available at: http://reports.eea.eu.int/ topic_report_2001_7)

Eifler W (1993) A hypothesis on momentum and heat transfer near the sea-atmosphere interface and a related simple model. J Mar Syst 4:133-153

Eppley RW, Stewart E, Abott MR, Heyman U (1985) Estimating ocean primary production from satellite chlorophyll: introduction to regional differences and statistics for the Southern California Bight. J Plankton Res 7:57-70

European Communities (2001a) Council Directive 91/271/EEC of 21 May 1991 concerning urban waste water treatment. Off J Eur Commun (OJEC) 135:40-52

European Communities (2001b) Council Directive 91/676/EEC of 12 December 1991 concerning the protection of waters against pollution caused by nitrates from agricultural sources. Off J Eur Commun (OJEC) 375:1-8

Ferreira JG (2000) Development of an estuary quality index based on key physical and biogeochemical features. Ocean Coast Manage 43:99-122

Fortier L, Le Fèvre J, Legendre L (1994) Export of biogenic carbon to fish and to the deep ocean: the role of large planktonic microphages. J Plankton Res 16:809-839

Garcia-Gorriz E, Hoepffner N, Ouberdous M (2003) Assimilation of SeaWiFS data in a coupled physical-biological model of the Adriatic Sea. J Mar Syst 40-41:233-252

Gerlach SA (1990) Nitrogen, phosphorus, plankton and oxygen deficiency in the German Bight and in Kiel Bay-final report on the project 'Eutrophication of the North Sea and the Baltic Sea'. Kiel Meeresforsch, Sonderh 7:1-341

Gohin F, Druon JN, Lampert L (2002) A five channel chlorophyll concentration algorithm applied to SeaWiFS data processed by SeaDAS in coastal waters. Int J Remote Sens 23:1639-1661

Gordon HR, McCluney WR (1975) Estimation of the depth of sunlight penetration in the sea for remote sensing. Appl Optics 14:413-416

Grall J, Glemarec M, Costello MJ, Wilson GJ, Emblow CS, Kelly KS (1997) Using biotic indices to estimate macroben- 
thic community perturbations in the Bay of Brest. Estuar Coast Shelf Sci 44:43-53

Gundersen JK, Jørgensen BB (1990) Microstructure of diffusive boundary layers and the oxygen uptake of the sea floor. Nature 345:604-607

Hagen NM, Kleeberg HB (1994) Optimum operation of restoration techniques for eutrophic water bodies. In: Newman AT (ed) Environmental impact of water resources developments recognition, evaluation and control. Kluwer Academic Publishers, Dordrecht, p 299-310

Harwood RR, Edwards CA, Lal R, Madden P, Miller RH, House G (1990) A history of sustainable agriculture. In: Edwards CA, Lal R, Madden P, Miller RH (eds) Sustainable agriculture systems. Soil and Water Conservation Society, Ankeny, IA, p 3-19

HELCOM (Helsinki Commission) (2003) The 2002 oxygen depletion event in the Kattegat, Belt Sea and western Baltic. Baltic Sea Environmental Proceedings, No. 90. Thematic report. Baltic Sea Environmental Protection Commission, Helsinki, p 1-64

Hickel W, Bauerfeind E, Niermann U, v. Westernhagen $\mathrm{H}$ (1989) Oxygen deficiency in the south-eastern North Sea: sources and biological effects. Ber Biol Anst Helgol 4:1-148

Joint I, Pomroy A (1993) Phytoplankton biomass and production in the North Sea. Mar Ecol Prog Ser 99:169-182

Jørgensen BB (1980) Seasonal oxygen depletion in bottom waters of a Danish fjord and its effects on the benthic community. Oikos 34:68-76

Josefson AB, Rasmussen B (2000) Nutrient retention by benthic macrofaunal biomass of Danish estuaries: importance of nutrient load and residence time. Estuar Coast Shelf Sci 50:205-216

Justić D (1987) Long-term eutrophication of the northern Adriatic Sea. Mar Pollut Bull 18:281-284

Justić D (1991) A simple oxygen index for trophic state description. Mar Pollut Bull 22:201-204

Lancelot C (1995) The mucilage phenomenon in the continental coastal waters of the North Sea. Sci Total Environ 165:83-102

Lassus P, Bardouil M, Berthomé JP, Maggi P, Truquet P, Le Déan L (1988) Seasonal occurrence of Dinophysis sp. along the French coast between 1983 and 1987. Aquat Living Resour 1:155-164

Lundsgaard C, Olesen M (1997) The origin of sedimenting detrital matter in a coastal ecosystem. Limnol Oceanogr 42:1001-1005

Mageau C, Barbière J (2003) The role of indicators in integrated coastal management-preface. Ocean Coast Manag 46:221-223

Malej A (1993) Ipossie e anossie nel Golfo di Trieste. In: Orel G, Fonda Umani S, Aleffi F (eds) Ipossie e anossie di fondali marini: l'Alto Adriatico e il Golfo di Trieste. Regione Autonome Friuli-Venezia Giulia, Ricci, Trieste, p 63-77

Marasovic I, Pucher-Petkovic T, Alegria V (1988) Relation between phytoplankton productivity and Sardina pilchardus in the middle Adriatic. In: Caddy JF, Savini M (eds) Report of the fifth technical consultation of the general fisheries council for the Mediterranean on stock assessment. Food and Agriculture Organization, FAO Fisheries Report 394, Rome, p 121-126

Ménesguen A, Hoch T (1997) Modelling the biogeochemical cycles of elements limiting the primary production in the Channel (N, P, Si): I. The role of thermohaline stratification. Mar Ecol Prog Ser 146:173-188

Monbet Y (1992) Control of phytoplankton biomass in estuaries: a comparative analysis of microtidal and macrotidal estuaries. Estuaries 15:563-571

Moriki A, Karydis M (1994) Application of multicriteria choicemethods in assessing eutrophication. Environ Monit Assess 33:1-18

Niermann U (1990) Oxygen deficiency in the south eastern North Sea in summer 1989. International Council for the Exploration of the Sea (ICES), Copenhagen

Nixon SW (1992) Quantifying the relationship between nitrogen input and the productivity of marine ecosystems. In: Takahashi M, Nakata K, Parsons TR (eds) Proceedings of Advanced Marine Technology Conference (AMTEC), Vol 5. AMTEC, Tokyo, p 57-83

Nixon SW (1995) Coastal marine eutrophication: a definition, social causes, and future concerns. Ophelia 41:199-219

NRC (National Research Council of USA) (2000) What determines susceptibility to nutrient over-enrichment? In: Committee on the Causes and Management of Coastal Eutrophication Ocean Studies Board and Water Science and Technology Board Commission on Geosciences, Environment, and Resources (ed) Clean coastal waters: understanding and reducing the effects of nutrient pollution. Commission on Geosciences, Environment, and Resources, National Academy Press, Washington, DC, p 163-194 (also available at: www.nap.edu/openbook/0309069483/html/ R1.html)

Olesen M, Lundsgaard C (1995) Seasonal sedimentation of autochthonous material from the euphotic zone of a coastal ecosystem. Estuar Coast Shelf Sci 41:475-490

O'Reilly JE, Maritorena S, Mitchell BG, Siegel DA, Carder KL, Garver SA, Kahru SA, McClain C (1998) Ocean colour chlorophyll algorithms for SeaWiFS. J Geophys Res 103: 24937-24953

Pohlmann T (1996) Predicting the thermocline in a circulation model of the North Sea. Part I. Model description, calibration and verification. Cont Shelf Res 16:131-146

Richardson K, Christoffersen A (1991) Seasonal distribution and production of phytoplankton in the southern Kattegat. Mar Ecol Prog Ser 78:217-227

Richardson K, Heilmann JP (1995) Primary production in the Kattegat: past and present. Ophelia 41:317-328

Richardson K, Nielsien TG, Pedersen FB, Heilmann JP, Løkkegaard B, Kaas H (1998) Spatial heterogeneity in the structure of the planktonic food web in the North Sea. Mar Ecol Prog Ser 168:197-211

Riegman R (1995) Nutrient-related selection mechanisms in marine phytoplankton communities and the impact of eutrophication on the planktonic food web. Water Sci Technol 32:63-75

Rosenberg R, Loo L, Möller P (1992) Hypoxia, salinity and temperature as structuring factors for marine benthic communities in a eutrophic area. Neth J Sea Res 30: 121-129

Rydberg L, Edler L, Floderus S, Graneli W (1990) Interaction between supply of nutrients, primary production, sedimentation and oxygen consumption in SE Kattegat. Ambio 19:134-141

Silver MW, Gowing MM, Davoll PJ (1987) The association of photosynthetic ultraplankton with pelagic detritus through the water column (0-2000 m). Can Bull Fish Aquat Sci 214:311-341

Šimunović A, Piccinetti C, Zore-Armada M (1999) Kill of benthic organisms as a response to an anoxic state in the northern Adriatic (a critical review). Acta Adriat 40:37-64

Skei J, Larsson P, Rosenberg R, Jonsson P, Olsson M, Broman D (2000) Eutrophication and contaminants in aquatic ecosystems. Ambio 29:184-194

Smayda TJ, Reynolds CS (2003) Strategies of marine dino- 
flagellate survival and some rules of assembly. J Sea Res 49:96-106

Sommer U, Stibor H, Katechakis A, Sommer F, Hansen T (2002) Pelagic food web configurations at different levels of nutrient richness and their implications for the ratio fish production:primary production. Hydrobiologia 484:11-20

Sturm B, Zibordi G (2002) SeaWiFS atmospheric correction by an approximate model and vicarious calibration. Int $\mathrm{J}$ Remote Sens 23:489-501

Thurow F (1999) On herring biomass in the Baltic Sea during the 20th century. ICES CM 1999/P:04

Tsirtsis G, Karydis M (1998) Evaluation of phytoplankton community indices for detecting eutrophic trends in the marine environment. Environ Monit Assess 50:255-269

Vidal M, Duarte CM, Sánchez MC (1999) Coastal eutrophication research in Europe: progress and imbalances. Mar Pollut Bull 38:851-854

Vollenweider RA, Giovanardi F, Montanari G, Rinaldi A (1998) Characterization of the trophic conditions of marine coastal waters with special reference to the NW Adriatic Sea: pro-

Editorial responsibility: Victor de Jonge (Contributing Editor), Haren, The Netherlands posal for a trophic scale, turbidity and generalized water quality. Environmetrics 9:329-357

Wassmann P (1990) Relationship between primary and export production in the boreal coastal zone of the North Atlantic. Limnol Oceanogr 35:464-471

Wassmann P (1998) Retention versus export food chains: processes controlling sinking loss from marine pelagic systems. Hydrobiologia 363:29-57

Weiss RF (1970) The solubility of nitrogen, oxygen, and argon in water and seawater. Deep-Sea Res 17:721-735

Wilson WS, Ball AS, Hinton RH (1999) Managing risks of nitrates to humans and the environment. Spec Publ 237. Royal Society of Chemistry, Cambridge

Worm B, Lotze HK, Hillebrand H, Sommer U (2002) Consumer versus resource control of species diversity and ecosystem functioning. Nature 417:848-851

Zurlini G (1996) Multiparametric classification of trophic conditions, the OECD methodology extended: combined probabilities and uncertainties - application to the North Adriatic Sea. Sci Tot Environ 182:169-185

Submitted: November 28, 2002; Accepted: December 1, 2003 Proofs received from author(s): April 15, 2004 